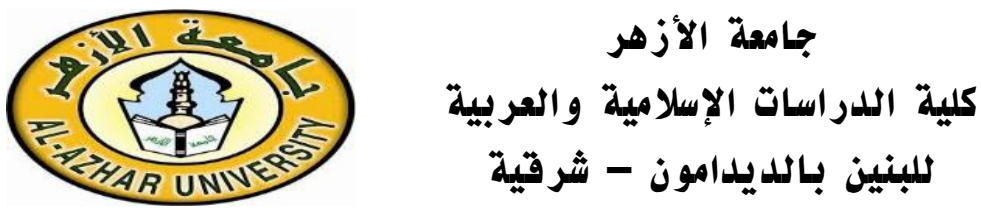

معالم الوسطية في علم أصول الفقه

$\partial$

إلمداص

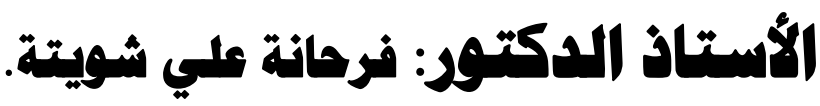

أستاذ أصول الفقه بكلية الدراسات الإسلامية والعريية

ل تلبنات بالمنصورة

المؤمتر العلمس الدولي الأول

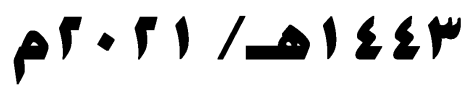


$-1794$. 


\section{معالم الوسطية هِّ علم أصول الفقه}

فرحانة علي ثويتة

قسم أصول الفقه- كلية الدراسات الإسلامية والعربية للبنات بالمنصورة

جامعة الأزهر. مدينة: المنصورة. الدولة: جمهورية مصر العربية.

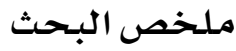

ملخص البحث: ملخدئ

تعتبر الوسطية أول خصائص الشريعة الإسلامية، وأكبر مقاصدها، ونحن يِّ أشد

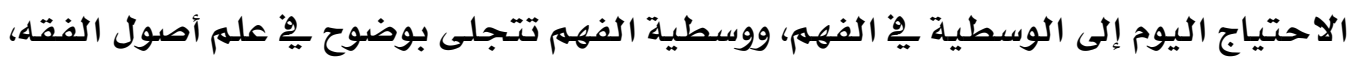

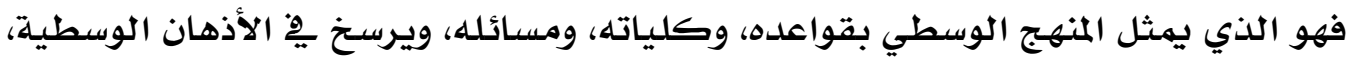

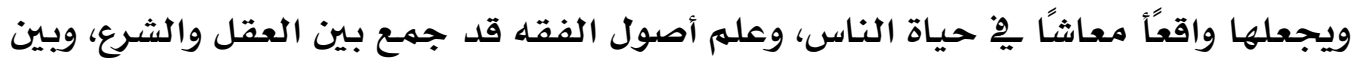

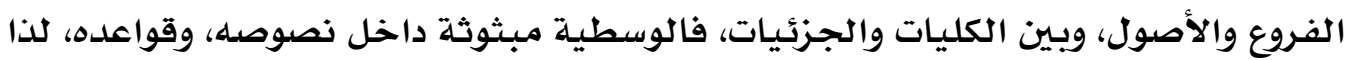

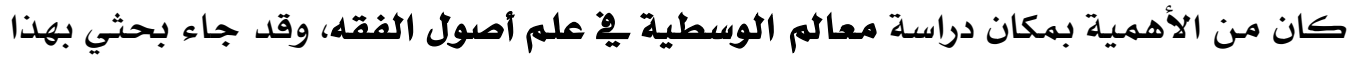

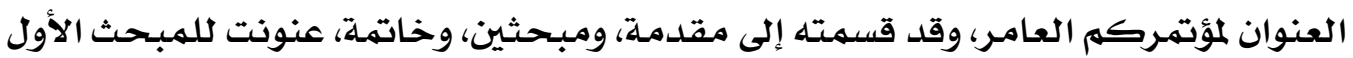
ببيان مفهوم الوسطية، وتأصيلها، وضوابطها، وطرق معرفتها منتظمًا ٍِِ أربعة مطالب، وأما

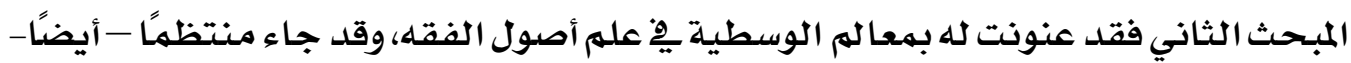

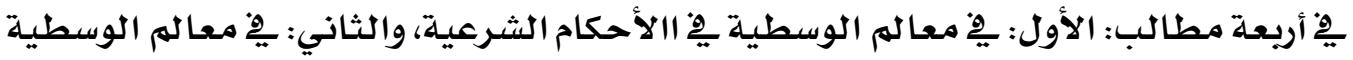

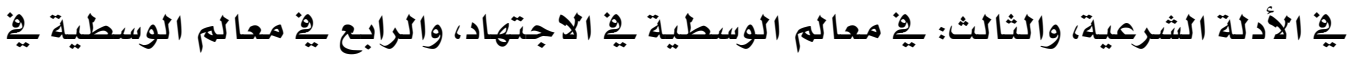
التقليد والفتوى.

الكلمات المفتاحية: الفتوى- أصول الفقه - الوسطية- الأحكام- الأدلة - الاجتهاد- 
Signs of moderation in the science of jurisprudence Farhana Ali Shweita

Department of Fundamentals of Jurisprudence, Faculty of Islamic and Arab Studies for Girls, Mansoura, Al-Azhar University, .city: Mansoura country: Egypt Abstract:

Moderation is the first characteristic of Islamic law, and its greatest purpose. Today, we are in dire need of moderation in understanding. The moderation of understanding is clearly manifested in the science of jurisprudence, as it is the one who represents the middle method with its rules, universals, and issues, and is firmly established in the minds of moderation. And makes it a reality in people's lives, and the science of jurisprudence has combined reason and Sharia, between branches and assets, and between universals and particulars, so moderation is embedded in its texts and rules. Therefore, it was of great importance to study the parameters of moderation in the Spring of jurisprudence, and my research came with this title for your abundant conference. It was divided into an introduction, two chapters, and a conclusion, titled to the first topic explaining the concept of moderation, its rooting, its controls, and ways to know it regularly in four demands. It also came regularly in four demands: the first: on the features of moderation in legal rulings, the second: on the features of moderation in legal evidence, the third: on the features of moderation in ijtihad, and the fourth on the features of moderation in imitation and fatwa.

\section{Key words:}

Fatwa "giving Sharia opinion" - Moderation- Original Rules- RulesEvidence- Ijtihad. 


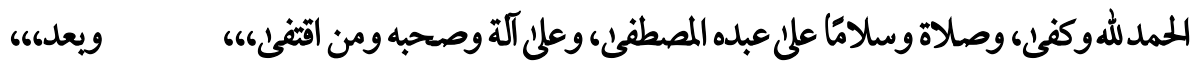
إن داء العصر الذي أصيبت به الأمة الإسلامية من مشرقها إلى مغربها هو البعد عن الاعتدال والتوسط، وقد عانت الأمة الإسلامية في كثير من القضايا المتعلقة بالفهم والسلوك، مما آدى إلى وصف الإسلام والمسلمين بالتطرف، والإرهاب، والغلو. وعلم أصول الفقه بقواعده ومسائله هو الذي يمثل الدواء، ويمثل المنهج الوسطي المستمد من معالم الوسطية في الشريعة، وهذا المنهج المتمثل في القواعد والكليات يرسخ في الأذهان "الوسطية"، وييعلها واقعا معاثا في حياة الناس، وسنة متبعة في تصرفاتهم، فهو العلم الذي ازدوج فيه العقل والسمع، واصطحب فيه الرأي والشرع، فأخذ من صفو الشرع والعقل سواء السبيل، فلا هو تصرف بمحض العقول الذي لا يتلقه الشرع بالقبول، ولا هو مبنيٌّ علني محض التقليد الذي لا يشهدله العقل بالتسديد والتأييد'.

والوسطية شاملة العقيدة، والأخلاق، والأحكام، معنى مبثوث داخل علم أصول الفقه وعليها قامت كلياته، وجزئياته، وفروعه، وأصوله، فهي آول خصائص الشريعة الإسلامية، وأكبر مقاصدها، والعالم الإسلامي اليوم في آشد الاحتياج إلى الوسطية في الفهم. من هنا جاءت أهمية البحث المعنون له ب "معالمالوسطية في علم أصول الفقه" لمؤتمركم الموقر. وقد اقتضت طبيعة البحث أن يقسم إلى مقدمة، ومبحثين، وخاتمة. المقدمة تناولت فيها أهمية البحث وخطته ومنهجه. المبحث الأول: بيان مفهوم الوسطية، وتأصيلها، وضوابطها، وطرق معرفها، ويشتمل علنى المطالب 
المطلب الثالث: ضوابط الاحتكام إلى الوسطية. المطلب الرابع: طرق معرفة الوسطية. المبحث الثاني: معالم الوسطية في علم أصول الفقه، ويشتمل على المطالب الآتية: المطلب الأول: الوسطية في الأمكام الشرعية. المطلب الثاني: الوسطية في الأدلة الشرعية. المطلب الثالث: الوسطية في الاجتهاد. المطلب الرابع: الوسطية في التقليد والفتوىن. 


\section{المبجه الأول؛ بيان مفهوم الوسطية، وتاصيلها، وضوابطها، وطرق معرفتها، ويشتمل}

على المطالب الآتية:

\section{المطلب الأول: تعريف الوسطية.}

الوسطية في اللغة: من مادة وسط، والواو والسين والطاء بناء صحيح يدل على العدل

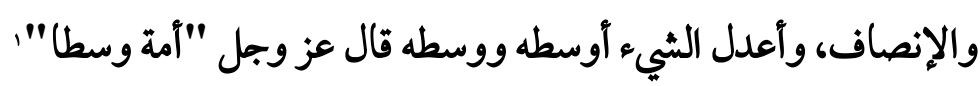

ووسط الشيء ما بين طرفيه، وأفضله وأعدله'، والوسط من كل شيء أعدله ونها وقال ابن الأثير:

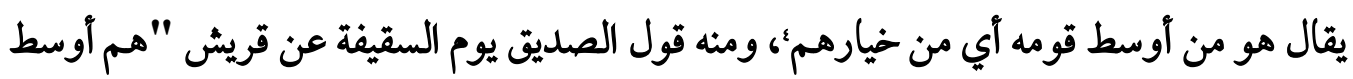

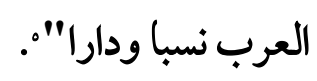

أما في الاصطلاح: فمصطلح الوسطية قليل الشيوع في كتب الفقه والأصول؛ لكن معناه موجودو مبثوث داخلها، فلكي نقف علن تحديد لمعنى الوسطية في الاصطلاح لابد آن نستحضر المعاني اللغوية، وقد دار لفظ الوسط بين معنين لغويين (العدل، والميار) وتفسير الوسطية بالعدالة والخيرية

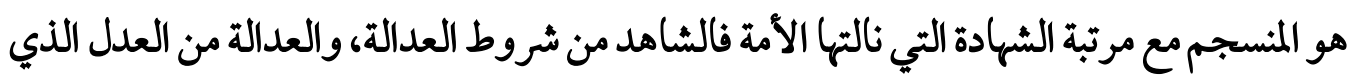

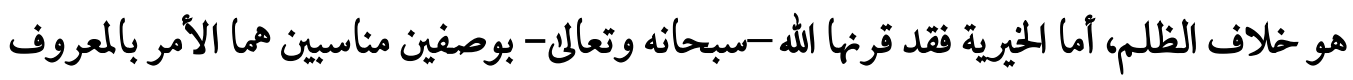

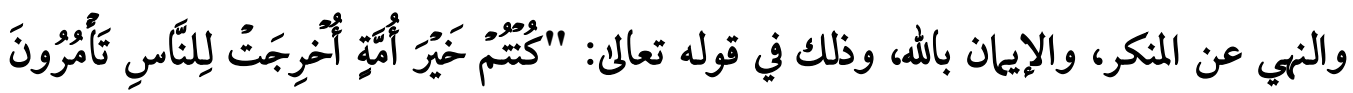

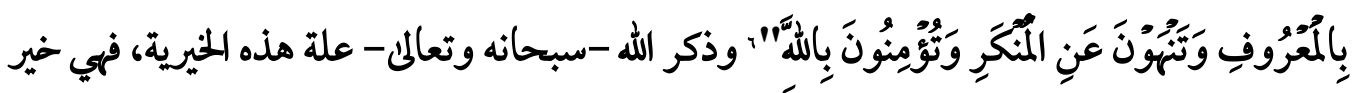

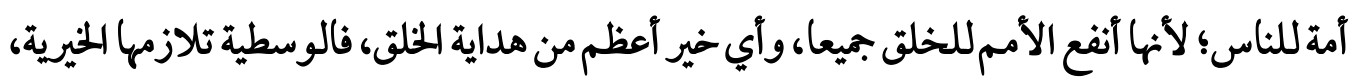

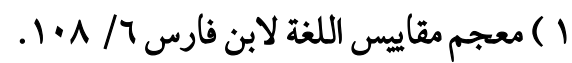

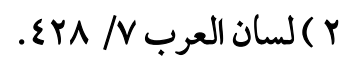

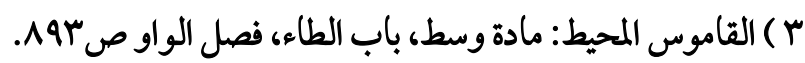

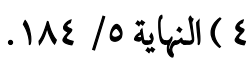

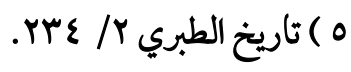

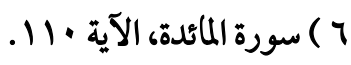


فلا وسطية بدون خيرية، ولا خيرية من غير عدل، فكل وسطية لابد لما من الخيرية والعدل، وبذلك

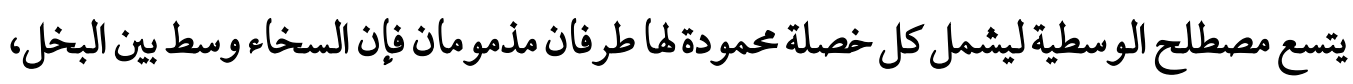

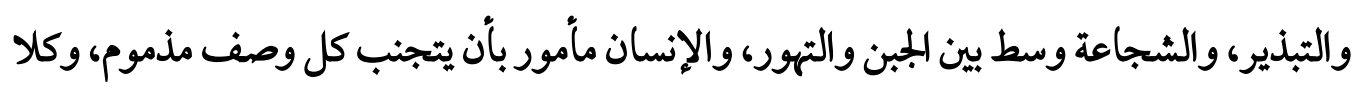
الطرفين وصف مذموم، ويبقى الخير والفضل للوسط'، ولا يلزم لكل ما يعتبر وسطا في الاصطلاح

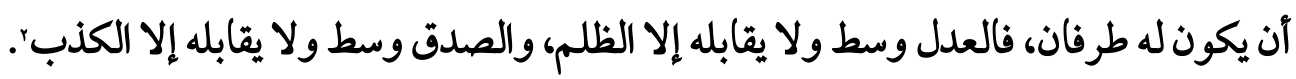

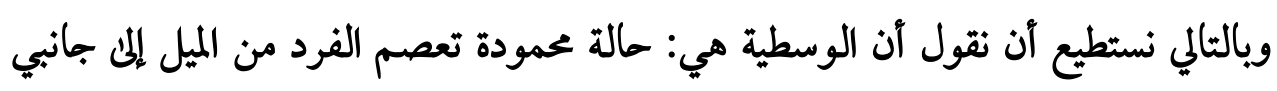

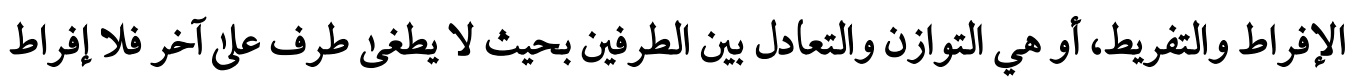
ولا تفريط ولا غلو ولا تقصير وإنما اتباع للأفضل و الأعدل.

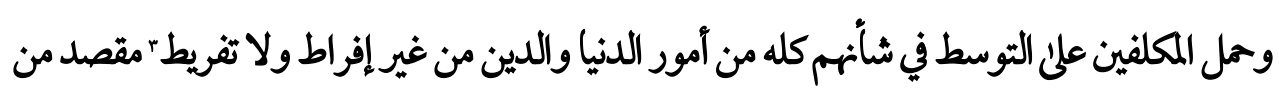
مقاصد الشرع المكيم من المكلفين، وأي خروج عن هذا الوسط هو في المقيقة خروج عن قصد الشارع.

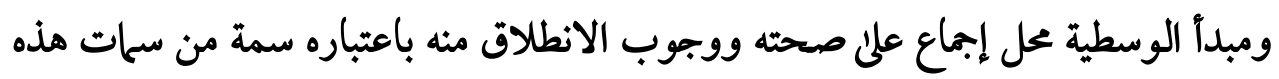

الشريعة الغراء.

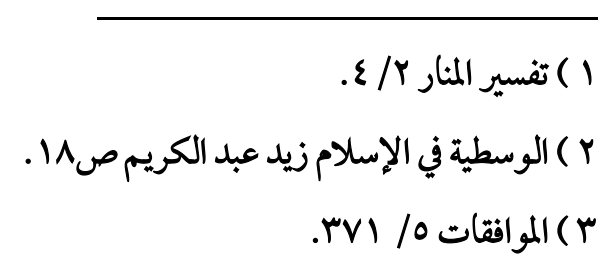




\section{المطلب الثاني: تاصيل مفهوم الوسطية.}

الوسطية أصل يرجع إليه وقاعدة كبرئ يحتكم إليها، وكلية من كليات الشريعة حيث ذكر الإمام

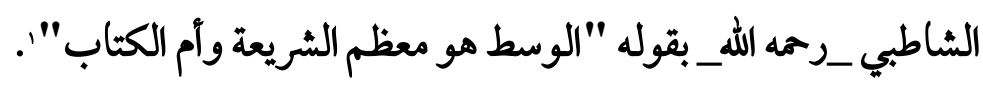

والأدلة على اعتبار الوسطية وإعلاما كثيرة، أهما:

أولاء : من القرآن الكريم:

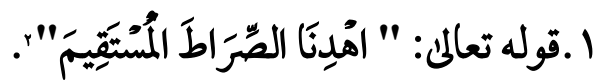

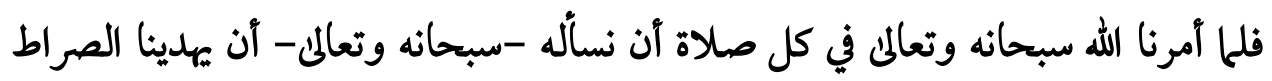

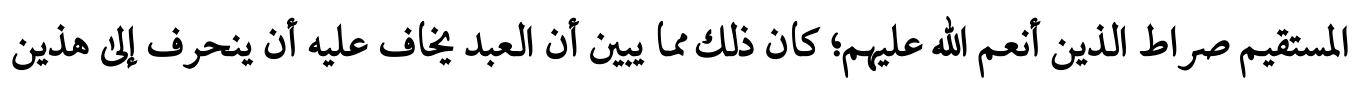
الطريقين ومما طريق المغضوب عليهم والضالين.

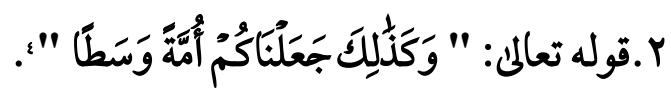

والوسطية شعار ميز لهذه الأمة وهو ما يستلزم منها ضرورة الإنصاف، والمراد بالوسط الخيار العدل، وروي عن أبي سعيد المدري رضي الله عنه عن رسول الله صلن الله عليه وسلم أنه قال:

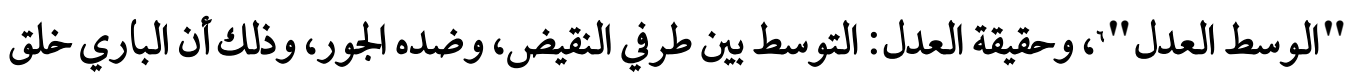

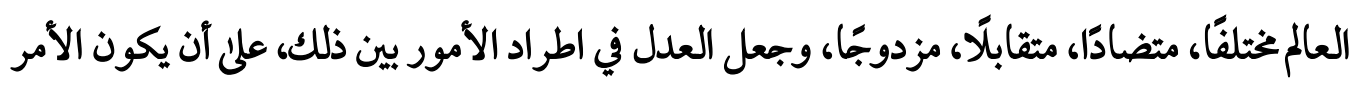

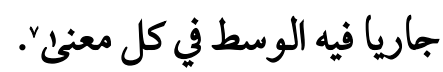

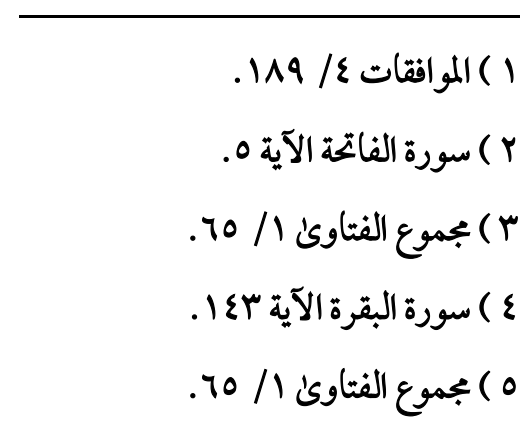

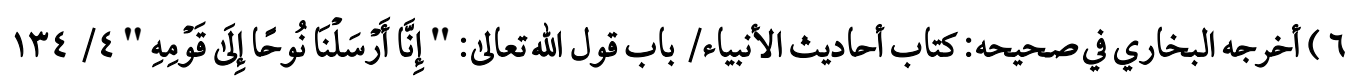
r

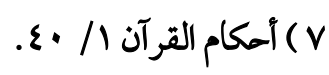




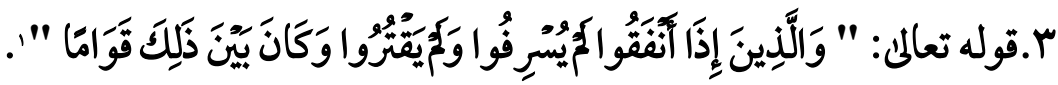

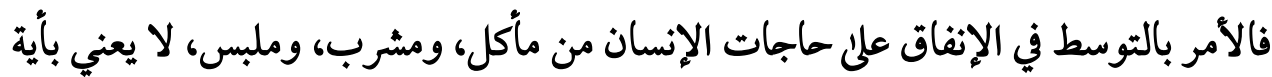

هال مخالفة طبيعته، أو معاكسة رغباته، وإنها المراد معلجة هذه الرغبات بـا يهفظ الإنسان.

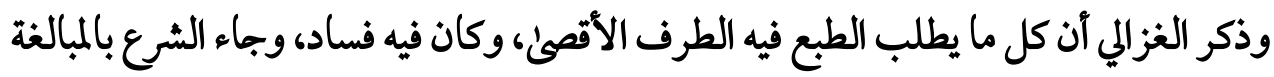

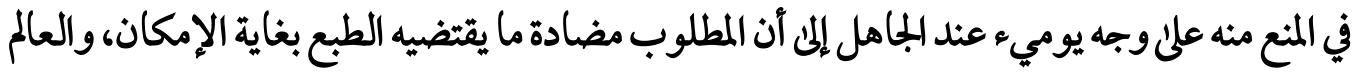
يدرك آن المقصود الوسط،....، فإن من يقدر علئ قمع الطبع بالكلية بعيد فيعلم آنه لا يتهي إلى الغاية،

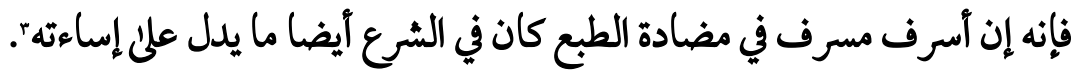
ولفظ وسط ومشتقاته ورد في مواضع كثيرة في القرآن الكريم، منها:

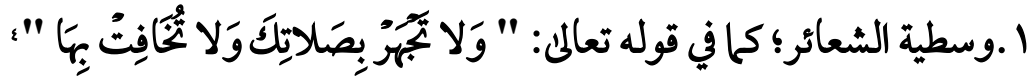

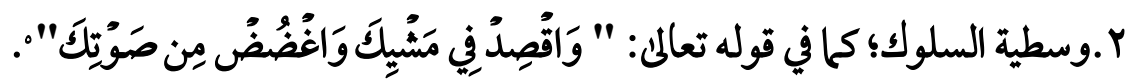

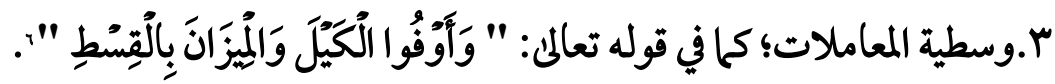

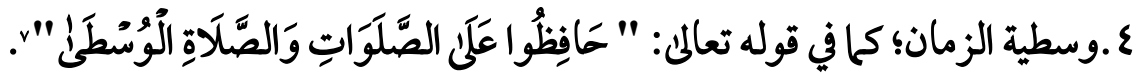

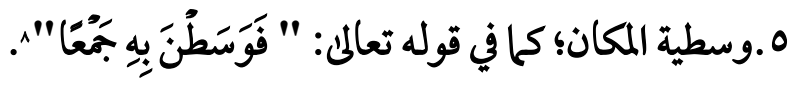

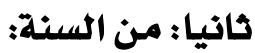

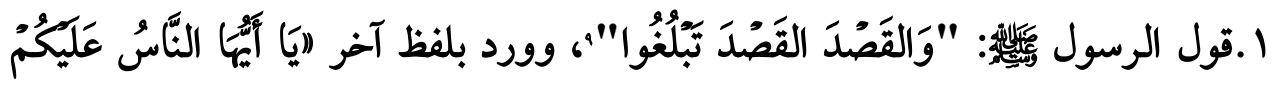

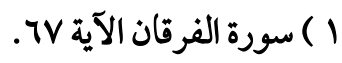

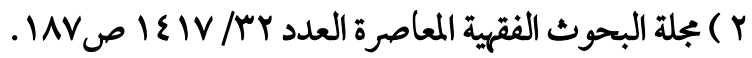

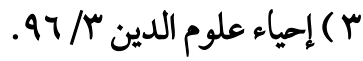

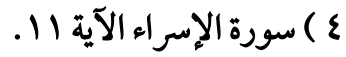

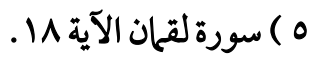

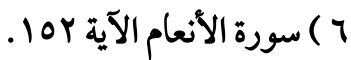

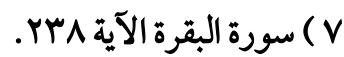

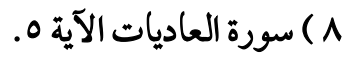

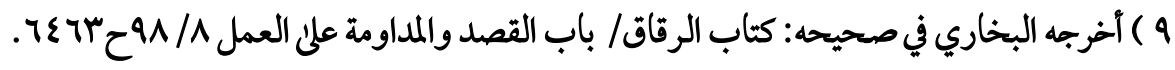




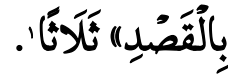

وجه الدلالة: ذكر ابن حجر في معنى قوله "القصد القصد تبلغوا" أي الزموا الطريق الوسط المعتله،

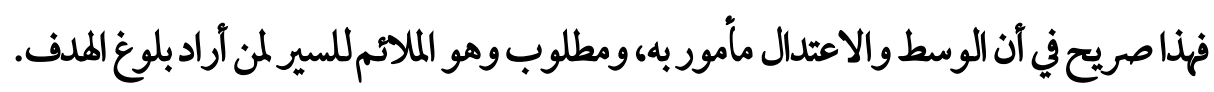

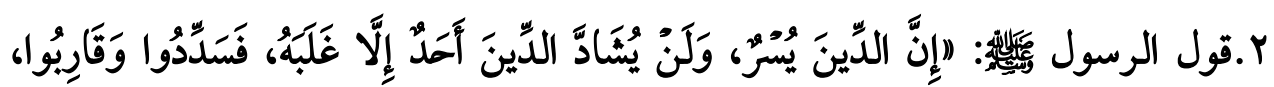

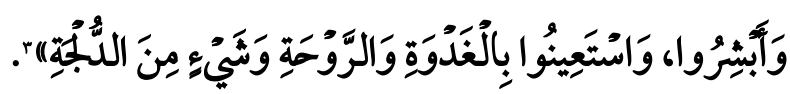

وجه الدلالة: قوله فسدووا وقاريوا يتمل آن يكون هذان اللفظان لمعنى واحد، ويحتمل آن يكونان

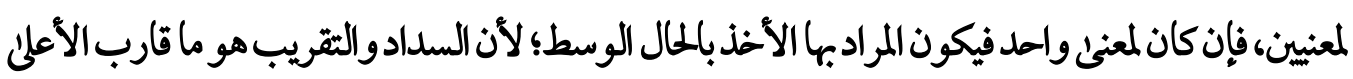

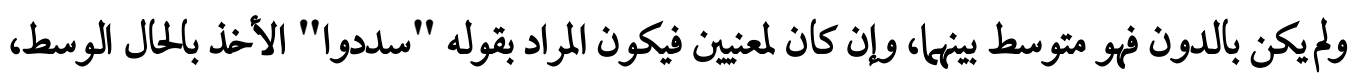

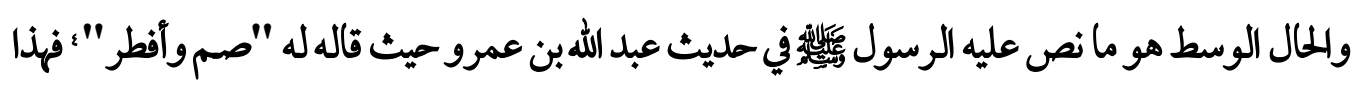

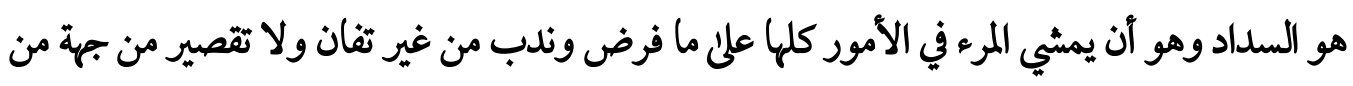

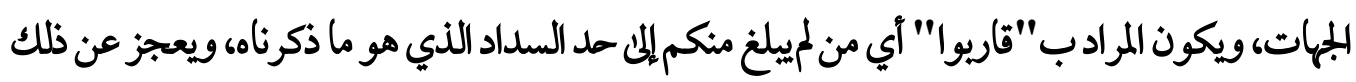
لعذر به فليقارب منه؛ لأن ما قرب من الثيء أعطي حكمهن.

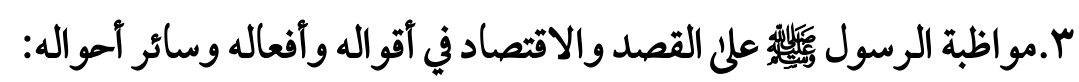

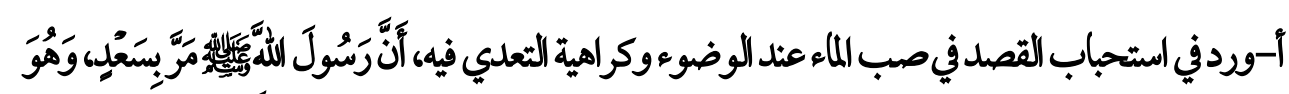

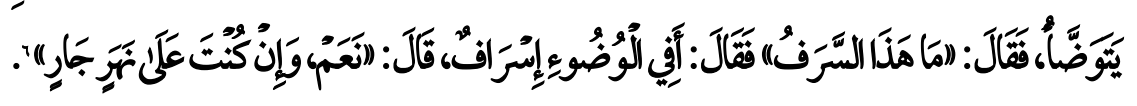

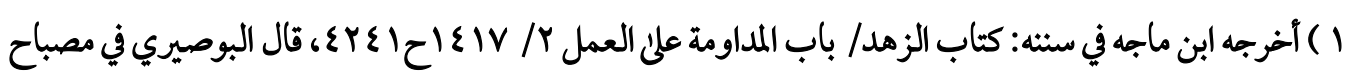

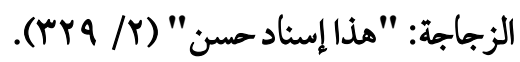

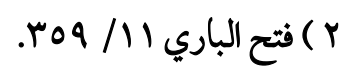

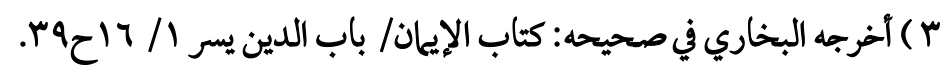

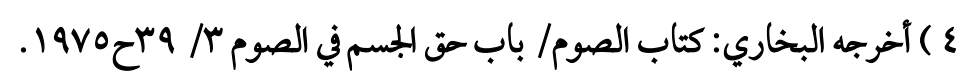

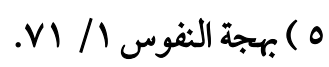

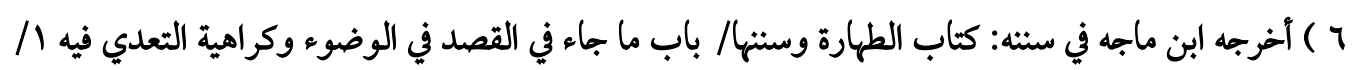

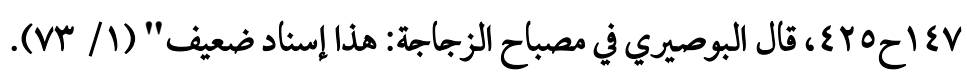




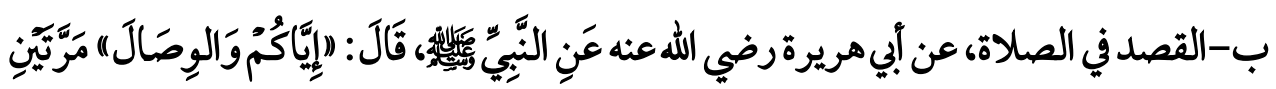

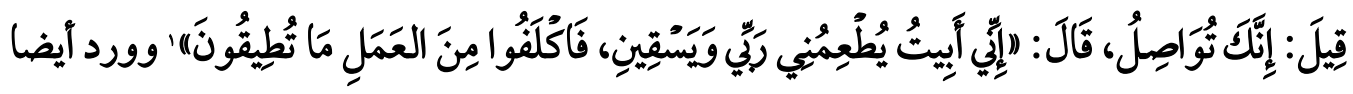

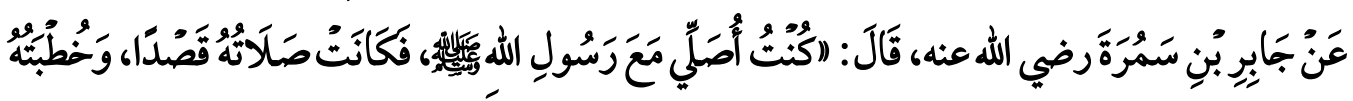
قَصَدَا آن.

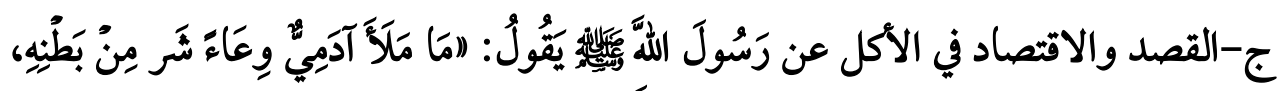

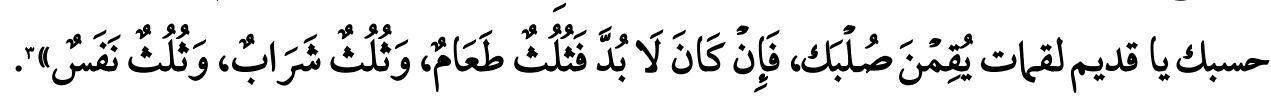
ثالثا: أقوال الصحابة:

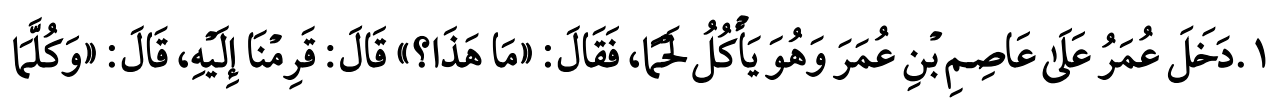

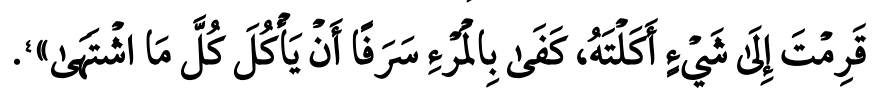

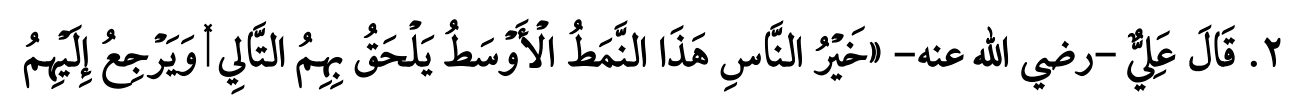
الْغَالِي". r. وصف عبد الله بن مسعود -رضي الله عنه- صحابة رسول الله

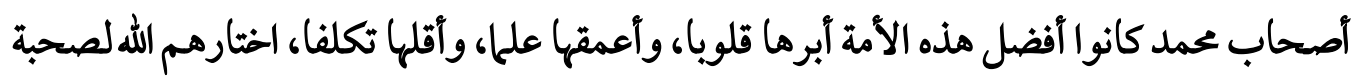

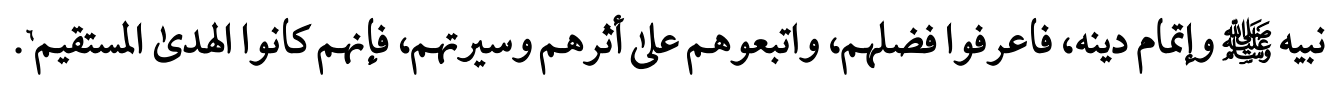
فالتوسط والاعتدال مطلوب ما أمكن، ومرجوع إليه، وتضافر على ذلك أقوال الصحابة، ومن بعدهم التابعين وتابع التابعين.

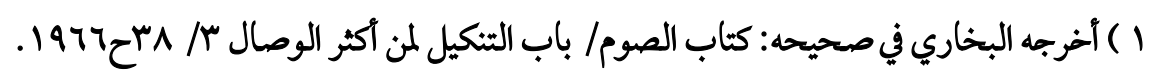

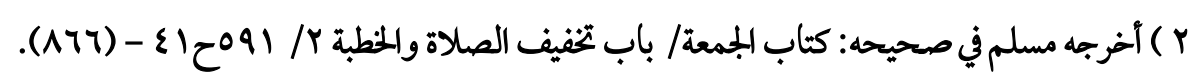

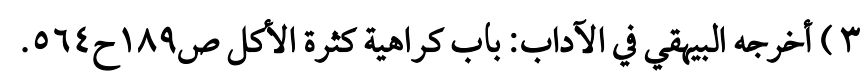

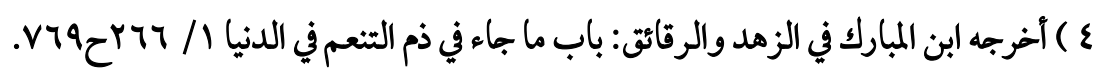

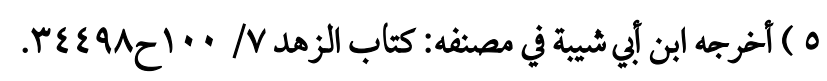

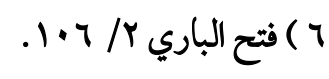


وقد ذكر الرازي: "إن في كل خلق من الأخلاق طرفي تفريط وإفراط ومما مذمومان والمق هو الوسط ذلك لأن الوسط هو العدل والصواب". وقال ابن القيم: "ما أمر الله بأمر إلا وللشيطان فيه نزعتان؛ إما إلى تفريط وإضاعة، وإما إلى إلى

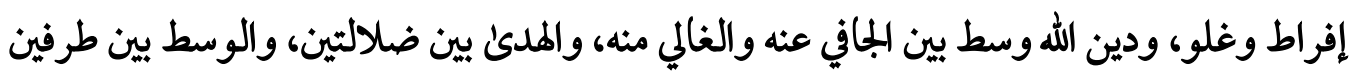

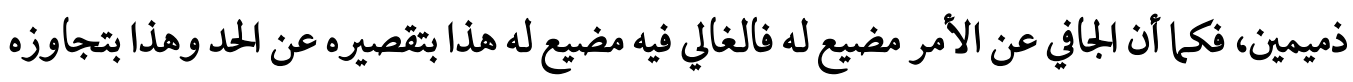
الحدن. 


\section{المطلب الثالث: ضوابط الاحتكام إلى الوسطية.}

المراد بالضوابط: القواعد التي تضع المدود، والشروط للعمل بالتوسط والاحتكام إليه، ومن

دون هذه الضوابط يكون المرء سالكا طريقًا غير طريق المداية.

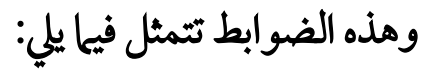

1.ألا يخالف الحكم بالتوسط منصوصا عليه:

فإذا كان الأخذ بالوسط في الأمور عامة هو خيرها وأفضلها؛ لأنها تحقق المصالح العاجلة والآجلة، فإن هذه المصالح لابد وأن تنطلق من الشرع، وتتقيد بقيوده، فكل مصلحة لا ترجع إلى همه حفظ مقصود فهم من الكتاب والسنة والإجماع، وكانت من المصالح الغريبة التي لا تلاتم تصرفات

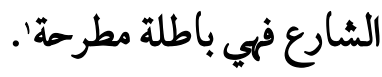

ومثال الأخذ بالتوسط الذي عارض النص الشرعي فاستحق بذلك المدر والإلغاء ما وردعن

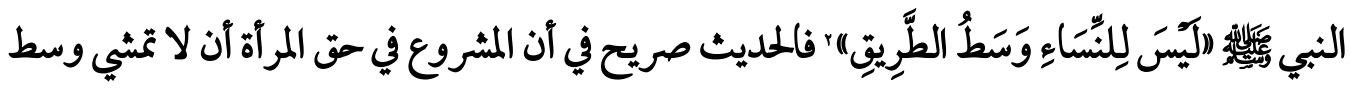
الطريق مزاحة للرجال، ومن ثم فإن الاستمساك بالوسط هنا خخالف لهدي الإسلام، وأيضا قول

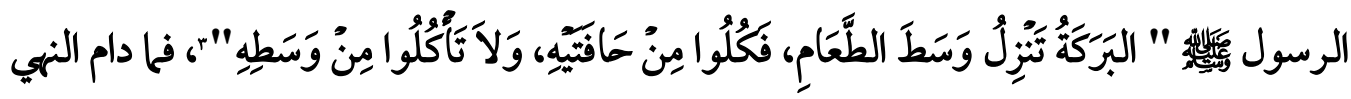
واردعن الأكل من وسط الآنية فليس بمستقيم أن يحتج أحد بأن الخير والبركة في الوسط. r. rأن يراعى يُ الأخذ بالوسطية الخيرية: فالوسطية دليل الخيرية، ومظهر الفضل والتمييز، ولكن هذه الخيرية لا تنال إلا بعلتها، والتي منها الأمر بالمعروف والنهي عن المنكر وليس التساهل، ولا شك آن الاسترسال في التساهل في

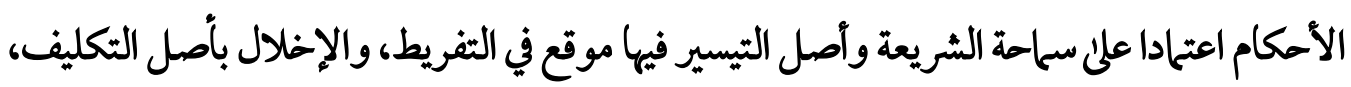

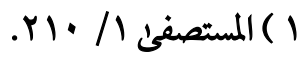
Y Y اخرجه ابن حبان في صحيحه: كتاب المظر والإباسة/ ذكر الزجر عن أن تشثي المرأة في هاجتها في وسط الطريق $.07 \cdot 1 \tau^{\varepsilon 10 / 1 r}$

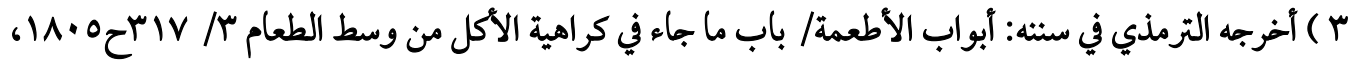

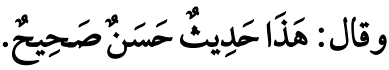


ومدعاة للهوئ، ونزعات النفس، وهذا منكر جاءت الشريعة بحسم مادته، فليس من ضرورة التوسط اللجوء إلى التيسير مطلقا، فالتيسير روح، والنصوص جسد لمذات التهات الروح، فلا يعتني بالروح

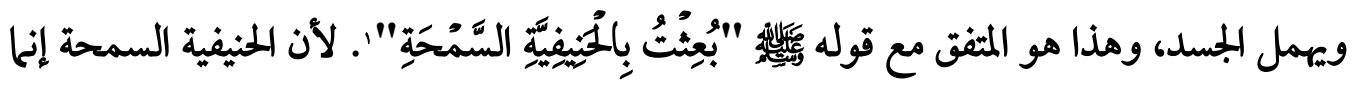
أتىل فيها السلحاح مقيداً بها هو جار على أصولمان.

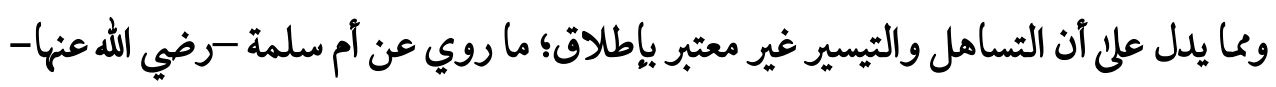

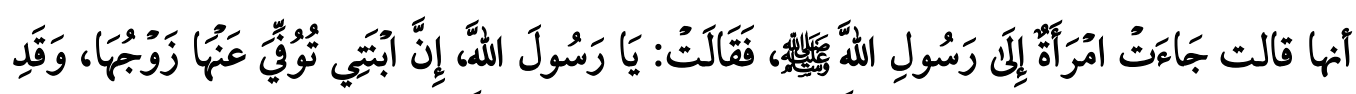

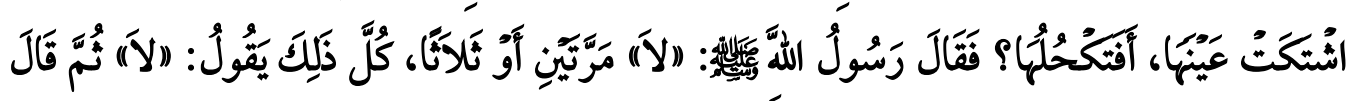

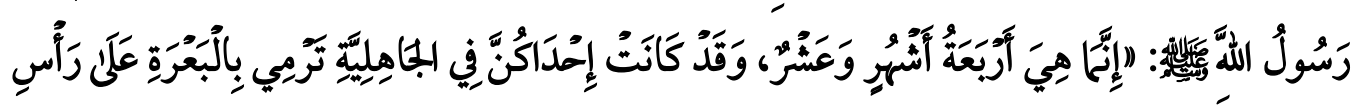
الحوّلِّ)"، فلم يسمح للحادة بالاكتحال لمجرد التداوي؛ لأن ذلك قد يتخذ ذريعة من بعض النساء

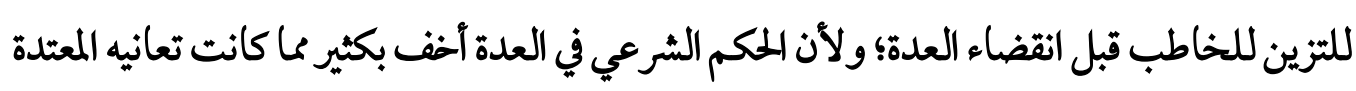
في الجاهلية.

\section{r.مراعاة الموازنة الدقيقة:}

فالوسطية تعني العدل، وإقامة الوزن والميزان بالقسط، وهذا أمر دقيق يحتاج إلى البصر بحقيقة الأطراف، ومقاديرها، وأحو الما، ثم الموازنة بينها بحكمة، ودقة تحتاج إلى عناية الله، ثم ضبط الأمر

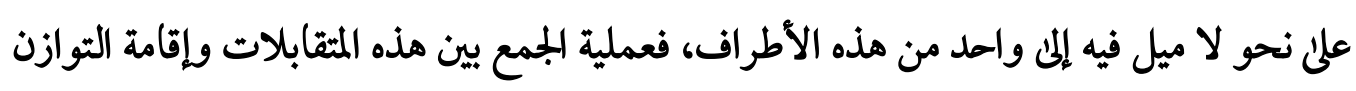

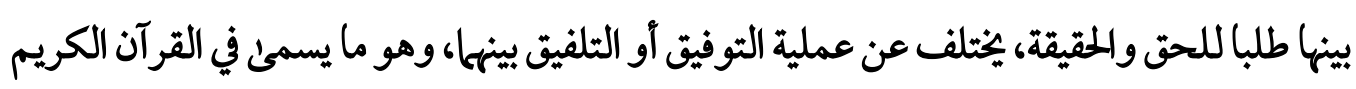
بالنفاق، وهو مزلق وانحراف عن الوسطية، يظن صاحبه أنه ييمع بين الطرفين، فعملية الموازنة

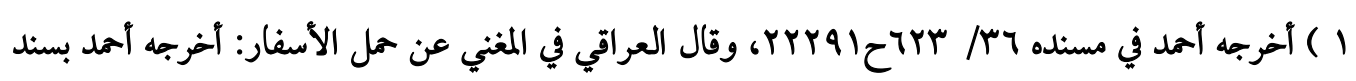

$$
\text { ضعيف. (ص) الموافقات \& \& \& ) ). }
$$

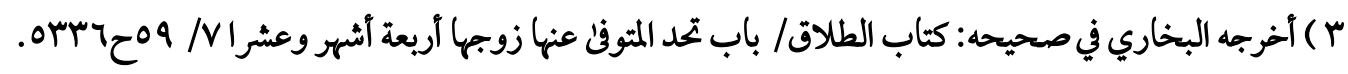

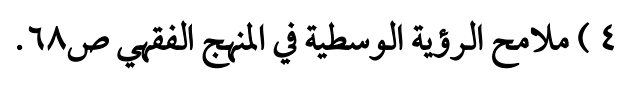


تتطلب الحذر واليقظة، كي لا ينحرف المرء إلى جانب علئ حساب الجانب الآخر، فيفقد التوازن، أو

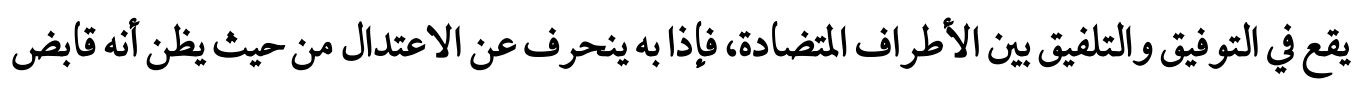

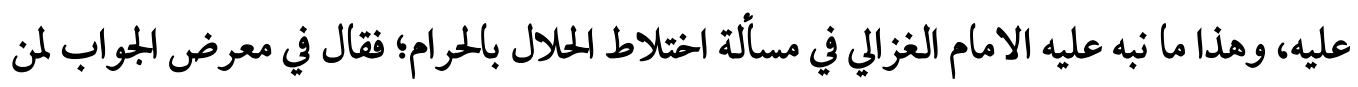
قال بأن أكثر الأموال حرام في زمانه إنه غلط محض منشؤه الغفلة عن الفرق بين الكثير والأكثر؛ فأكثر

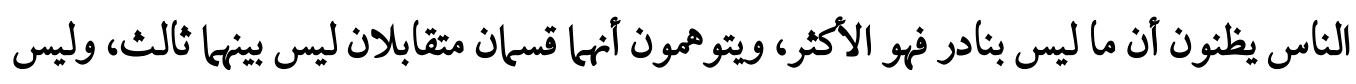

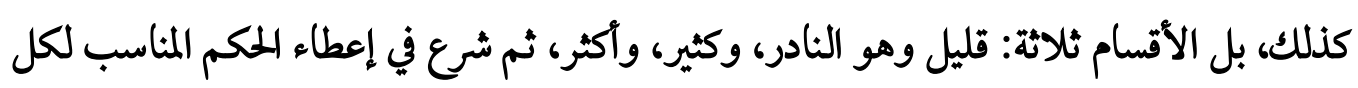
واحد من هذه الدرجات 


\section{المطلب الرابع ؛ طرق معرثة الوسطية.}

إن معرفة الوسط وتحديده أمر تتجاذبه أطراف متقابلة؛ لا تخضع للكم والعدد، ومن ثم يظل

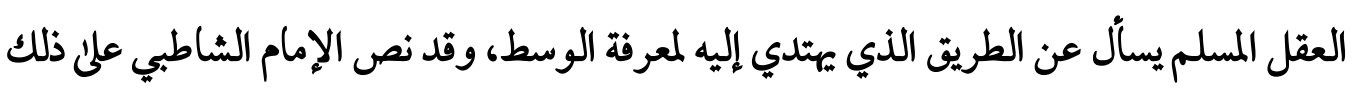
بقوله: "والتوسط يعرف بالشرع، وقد يعرف بالعوائد، وما يشهد به معظم العقلاء"، ومن خلماليال قول الشاطبي نستطيع أن نقول أن الطرق التي تعرف من خلالا الوسطية ما يلي:

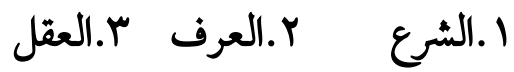

أولا: معرفة الوسطية بالشرع:

والشرع هو الأصل في معرفة الوسطية؛ وقد شهد لمذه الأمة بأنها أمة الوسط، فقال تعالى: "

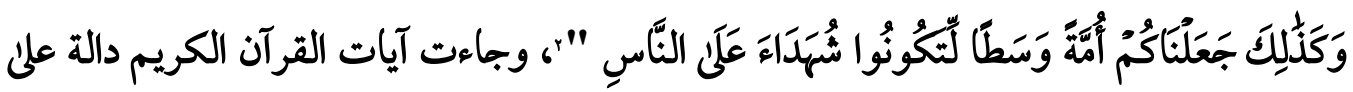
اعتبار الوسطية؛ فمن ذلك:

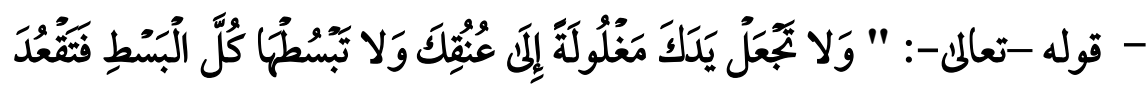

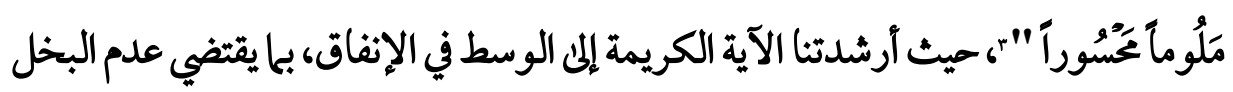

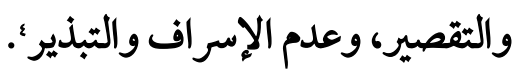

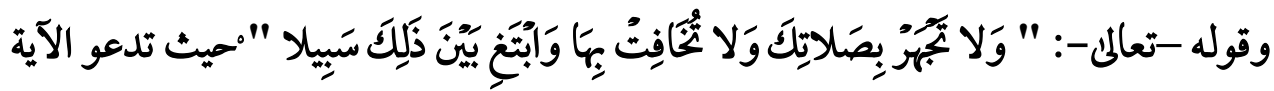

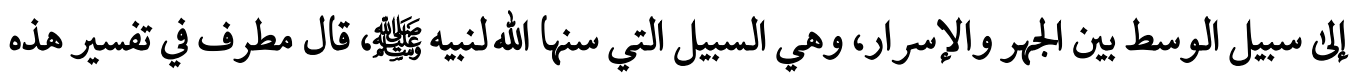
الآية: أن العلم خير من العمل وخير الأمور أوسطها والحسنة بين تلك السييتين'؛ لأن الله تعالى يقول:

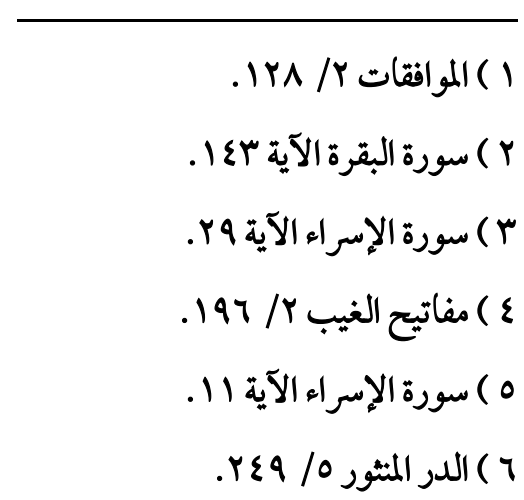


"ولا تجر بصلاتك ولا تخافت بها"، وذكر أبي قلابة في تفسير الآية: خير الأمور أوسطها'، وذكر ابن

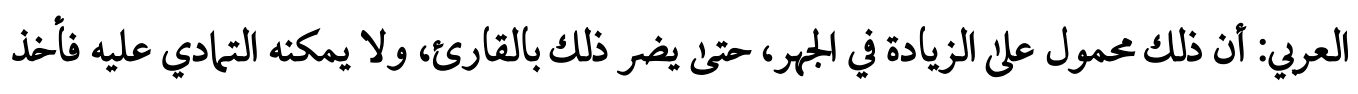
بالوسط من الجهر المتعب والإسرار المخافت.

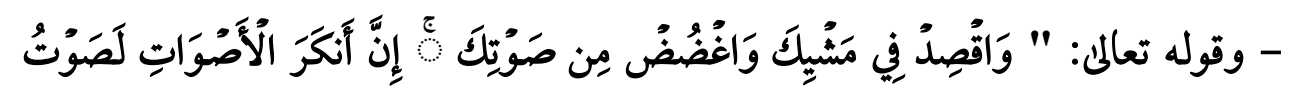
الحُمِيرِ"، حيث دلت الآية دلالة واضحة على الأمر بالتوسط والاعتدال في شيئين:

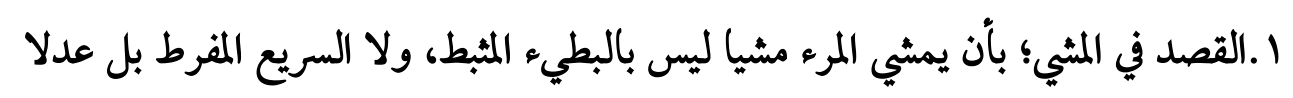

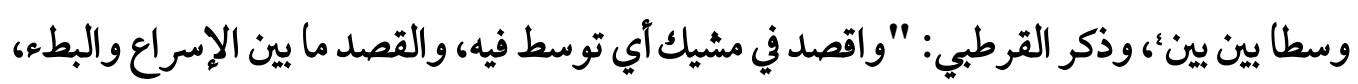

$$
\text { أي لا تدب دبيب المتحاوتين ولا تثب وثب الشطار. }
$$

r. الصوت؛ وذلك بأن ينقص المرء منه في رفعة، ولا يتكلف وليأخذ منه ما يحتاج إليه فإن المجهر بأكثر من الحاجة تكلف يؤذي،.

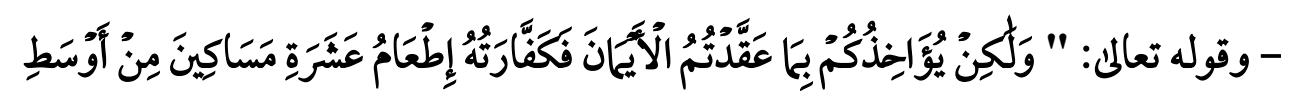

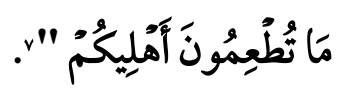
فبعد أن ساق الإمام الطبري آقوال المفسرين واختلافهم في معنى الوسط قال: "وأولى الأقوال

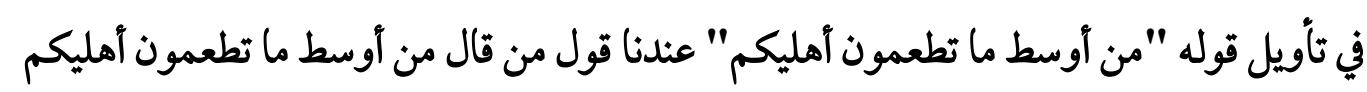
في القلة والكثرة، والآيات القرآنية التي تدل علئ الوسطية كثيرة، كالآيات الناهية عن الغلو،

(1) كثف المقا / / ك9 ع.

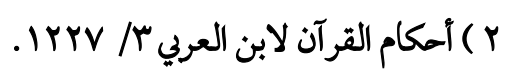

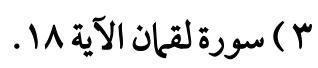

ع ) تفسير القرآن العظيم / / 1 /

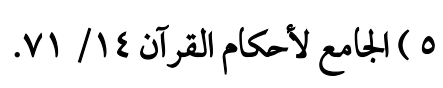

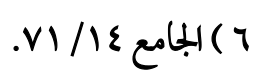

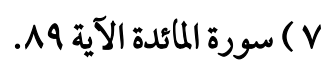

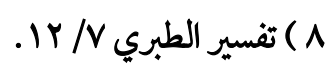


والمحذرة من تعدي الحدود، والآيات الآمرة بالعدل ولزوم القسط، فكل طريق يوصل إلى إقامة

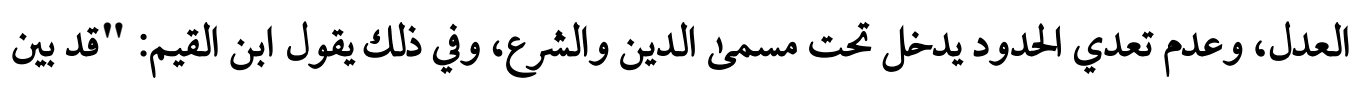
الله سبحانه وتعالم بـا شرعه من الطرق أن مقصوده إقامة العدل بين عباده، وقيام الناس بالقسط فأي لعاي طريق استخرج بها العدل والقسط فهي من الدين وليست مخالفة له . فالشريعة جاءت بالوسط في كلياتها وجزئياتها؛ وهو ما أوجب الأخذ بالتوسط في شئون التون الحياة كلها، والآيات والأحاديث التي ترشد إلى أن التوسط هو مقتضئ الخطاب كثيرة جدا. ثانيا: معرفة الوسطية بالعرف: العرف هو ما استقرت النفوس عليه بشهادة العقول وتلقته الطبائع بالقبول،، وقيل: هو ما استمر الناس عليه علنم حكم العقول وعادوا إليه مرة بعد آخرىن". وذكر الشاطبي أن العرف: هو ما تعارف عليه الناس من معاملات استقامت عليها أمورهم: فالعرف إذًا هو ما تعارفه الناس، واعتادوه في حياتهم من آقوال، وأعال، استقامت أمورهم بها، واتفقوا عليها، وساروا عليها في بجاري حياتهم. والمراد به هنا ما يتعارفه الناس وييري بينهم من وسائل التعبير، وأساليب الخطاب والكلام، وما

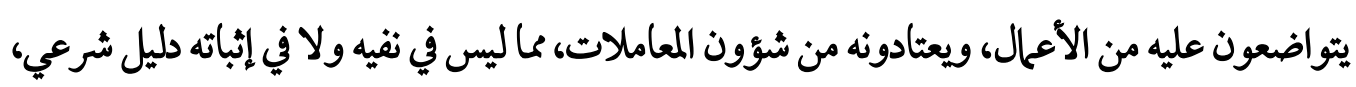

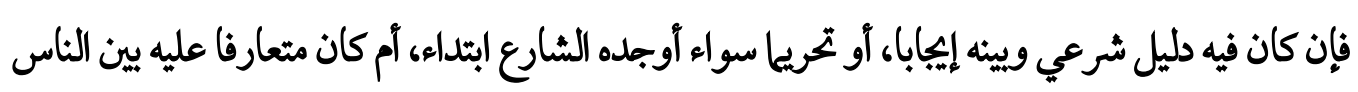
وأكده الشارع، فهذا ليس المقصودفي معرفة الوسط لأنه حيثذ معروف من الشرع.

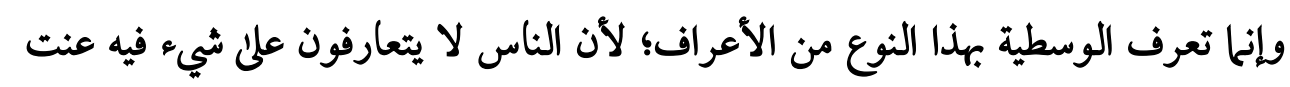
ومشقة وغلو وتطرف، وما ذاك إلا لآن التوسط مركوز في الفطرة الإنسانية.

1) الطرق المكمية في السياسية الشرعيةص717.

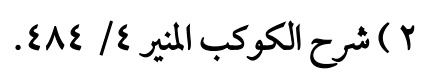

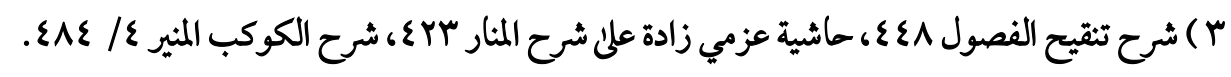
ع ع الموافقات ع ع ع.r. 
وقد بنى الفقهاء كثير من الأمكام على الوسطية المتبعة في الفرع، ومن ذلك ما ذكره ابن قدامه في اختلاف المتبايعين حيث قال: "فإن اختلفا في صفة الثمن؛ رجع إلى نقد البلد، لأن الظاهر أنها لا لا يعقدان إلا به، وإن كان في البلد نقود رجع إلى أوسطها'. ثالثا: معرفة الوسطية بالعقل:

-العقل نور في الصدر به يبصر القلب عند النظر في اللحجج، فهو بمنزلة السراج، فإنه نور تبصر

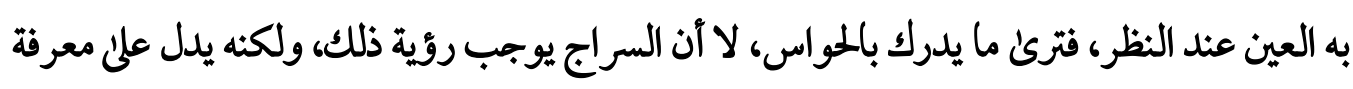

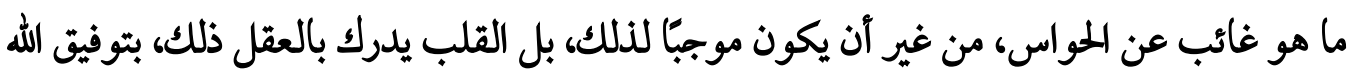

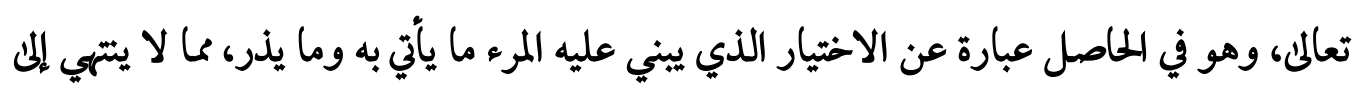

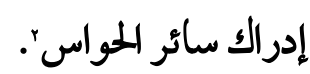

ومن تكريم التثريع الإسلامي للعقل أن جعله مناطًا للتكليف فلا يتوجه الخطاب الشرعي إلا

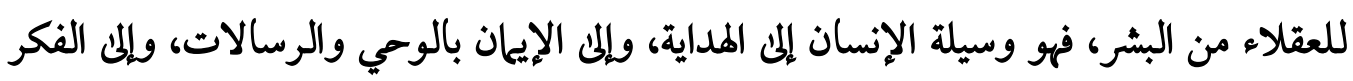

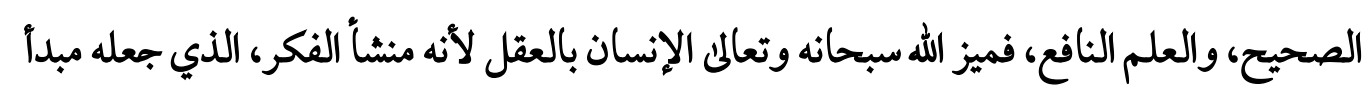
كمال الإنسان، وميزه بالإرادة، وقدرة التصرف والتسخير للكون، والحياة بـا وهبه من العقل، فالعقل الإنساني هو أداة الإدراك والفهم والنظر، والتلقي والتمييز والموازنة بين الخير والشر، والنفع والضررده.

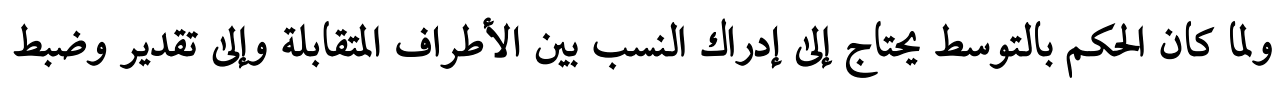
المصلحة خوف الانحراف، وهو ما يعرف بالتوازن أو الموازنة الدقيقة وهذا لا يعرف إلا بالعقل. وقد ذكر الفقهاء مسائل كثيرة أرجعوا الوسطية فيها إلى العقل منها:

( ) المغني لابن قدامة ع/ 9 9 I.

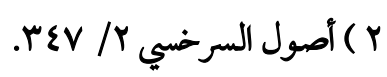

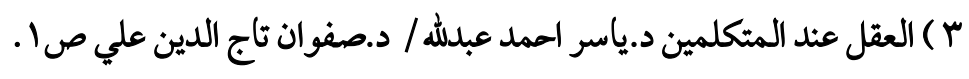


1. ما حكم به العقل في صدقة الأنعام فإن المصدق يأخذ من الوسط الذي يعلم بالنظر العقلي

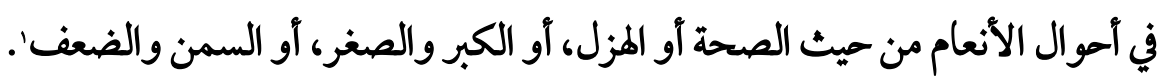

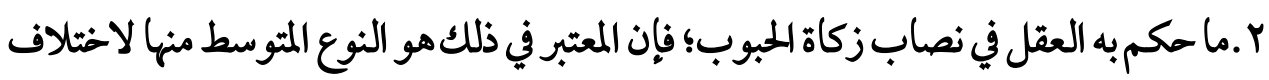

أوزانها، فمنها ما هو غاية في الثقل، ومنها ما هو غاية في الحفة، فالنظر العقلي هو المفضي إلى معرفة

المتوسط منها لتخرج منها الزكاة، ومثل هذا تقدير وزن القيراط بثلاث حبات من متوسط الشعيرَ. 


\section{المبعة الثاني : معالم الوسطية في علم أصول الفقل.}

إن علم أصول الفقه مرتبط بعلم الفقه، ومتكامل معه فالأول يهتم بالقواعد والأصول الكلية،

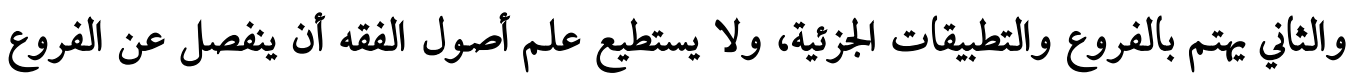

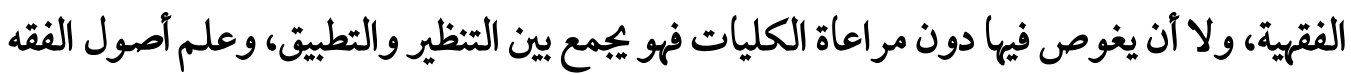

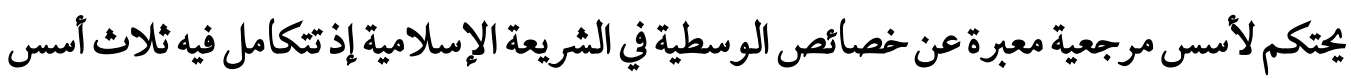
هي: الوحي، والعقل، والواقع. فالوحي هو المرجعية العليا اللحاكمة؛ وهذا لا يعني إهمال الأسس الأخرئ أو تجاهلها، فرغم آن

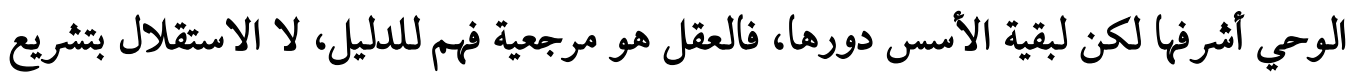

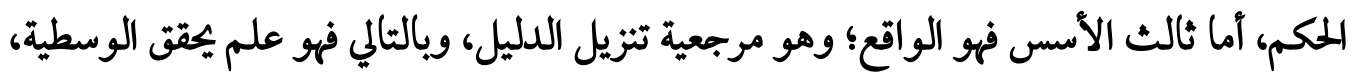
فجمع فقه التنزيل في الفهم، بفقه الواقع، بمراعاة مآله حال التنزيل. وسوف أوضح بعض مظاهر الوسطية في علم أصول الفقه في المطالب الآتية:

\section{المطلب الأول: الوسطية في الأمكام الشرعية.}

اللحكم الشرعي هو خطاب الله تعالمى المتعلق بأفعال المكلفين بالاقتضاء او التخيير او الوضع'.

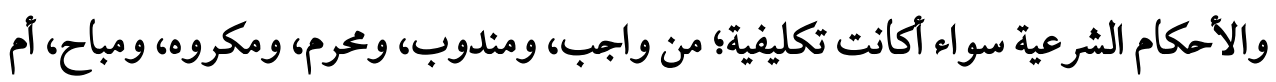
وضعية؛ من سبب، وشرط، ومانع، وصحة، وبطلان، وعزيمة، ورخصة، جارية علن التوسط

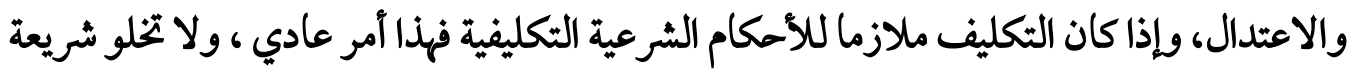
من ذلك، لكنها المشقة المعتادة التي إن داوم المكلف عليها لميلحقه ضرر، وهذا هو وجه الاعثدال والوسطية في التكاليف الشرعية. بالإضافة إلى أن شرط التكليف هو القدرة؛ ولهذا كانت تكاليف الشريعة مهمة، يمكن القيام بها من غير إعنات، وكانوا الصحابة -رضوان اللهعليهم- إذا نزل بهم حكم ثقيل في القرآن سألوا الله

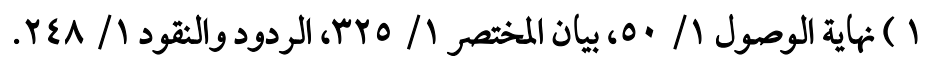




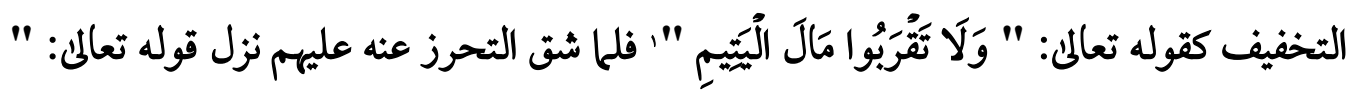

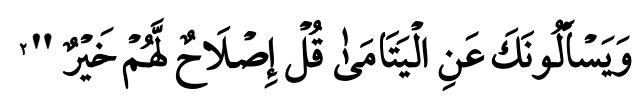

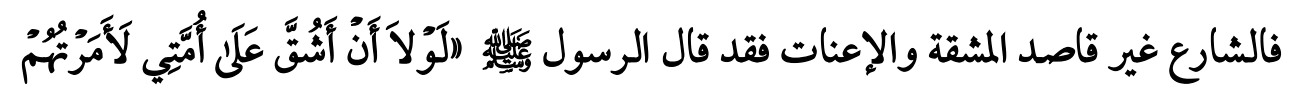

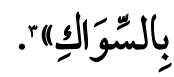

وذكر الشاطبي أن الشريعة جارية في التكليف بمقتضاها علن الطريق الوسط، الأعدل، الآخذ

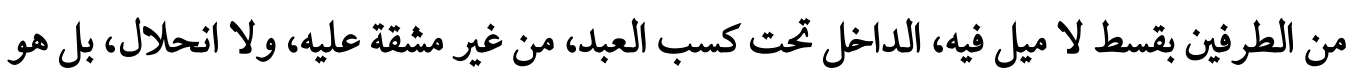
تكليف جار علن موازنة تقتضي في جميع المكلفين غاية الاعتدال، كتكاليف الصلاة، والصيام، والزكاة، والمج وغير ذلك، فإذا كان التشريع لأجل انحر اف المكلف، أو وجود مظنة انحر افه عن الوسط إلى الثي

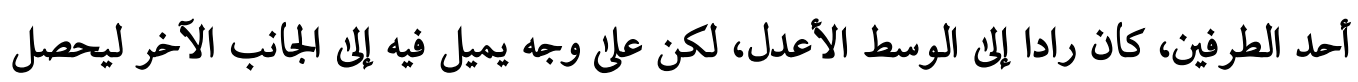

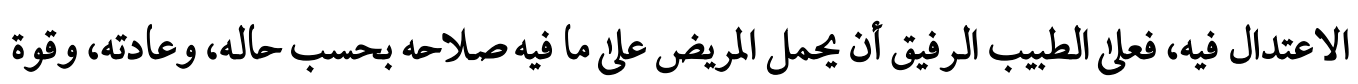
مرضه وضعفه، حتى إذا استقلت صحته هياً له طريقا في التدبير وسطا لائقا به في جميع أحواله أله ومن مظاهر وسطية الأمكام الشرعية ما يلي: أولاء التفاوت بِ رتب المأمورات: التفاوت هو: الاختلاف في الأوصاف كأنه يفوت وصف أحدمان الآخر، أو وصف كل منها

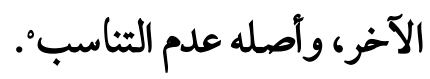
فالأوامر الشرعية إما آن تكون واجبات أو مندويات، والأصل في المأمورات الوجوب، وقد ترد إلى الندب، والندب أقل من الوجوب من حيث الطلب وغيره، والواجبات أقسام كثيرة

$$
\text { ( ) سورة الأنعام الآية ror. }
$$

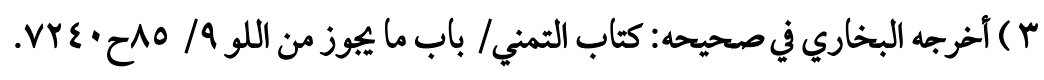

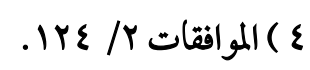

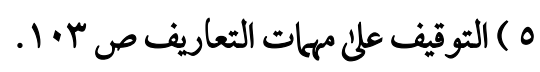


باعتبارات كثيرة؛ فمنها ما هو واجب مطلق وواجب مؤقت، وواجب محدد وغير محدد، وواجب معين ومخير، وعيني وكفائي، وكذلك تنقسم المندوبات إلى مندوبات مؤكدة، ونافلة، وزائدة' . ومما لا خلاف فيه بين العلماء آن هناك تفاوتًا بين الواجبات، والمندوبات في الرتب، فرتبة الواجب تزيد عن رتبة المندوب، وكذلك التفاوت في درجات الواجبات، لأنها مبنية على المصالح، وعلى رتب المصالح تترتب الفضائل، وبالتالي مصالح الواجب تكون أفضل من مصالح الندب؟. والدليل على التفاوت في رتب المأمورات قول الرسول

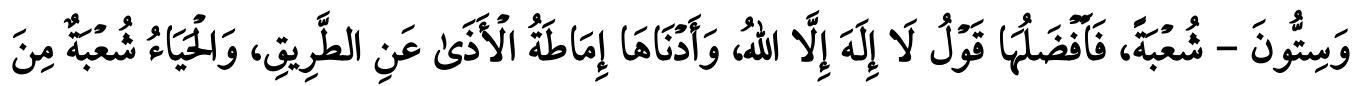

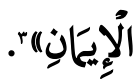
وذكر الغزالي أن ترك الترتيب بين اللخيرات من جملة الشرور، فعدم مراعاة رتب الواجبات، والمندويات قد يكون انحراف عن جادة الوسطء، والإخلال بمراتب الواجبات والمندويات لا يستحضر فيها الوسط. ويقول العز بن عبد السلام: وأعلى رتب مصالح الندب دون أدنى رتب مصالح الواجب، وتتفاوت إلى أن تنتهي إلى مصلحة يسيرة لو فاتت عنها لصادفنا مصالح المباحْ. ويعض المندويات كنلك آكد من البعض الآخر، فأعلى درجات المندوب هي السنة، ثمتليها الفضيلة، ثمتليها النافلة، والتالي يكون ترك هذه المندويات أعظم مفسدة من ترك بعض المندويات الأخرى".

\section{r. التفاوت ِِّ رتب المنهيات:}

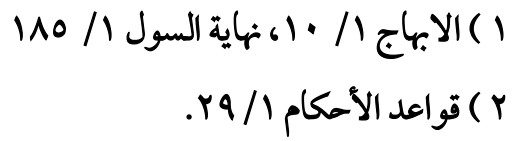

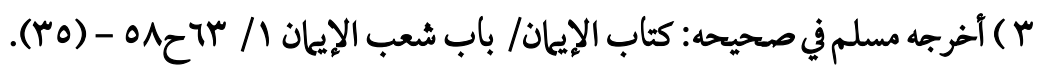
ع ) احياء علوم الدين r/ - 11.

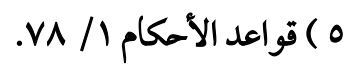

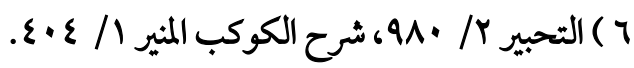


المنهيات إما أن تكون محرمات، أو مكروهات، والمحرمات منها الكبائر والصغائر، وقد ذكر

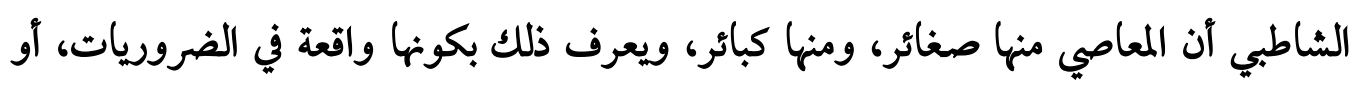

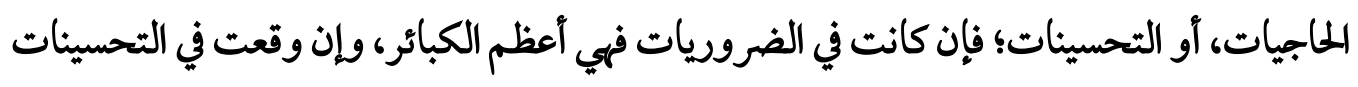

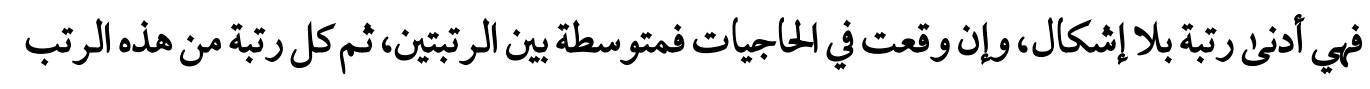

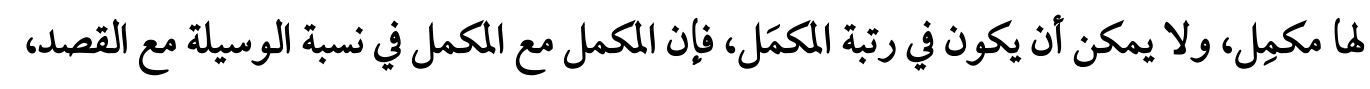
ولا تبلغ الوسيلة رتبة القصد، فقد ظهر تفاوت المعاصي والمخالفات.

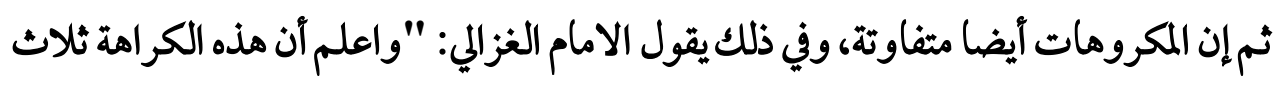
درجات؛ الأولى منها تقترب من الحرام، والورع منه مهم، والأخيرة تتهي إلى نوع من المبالغة تكاد

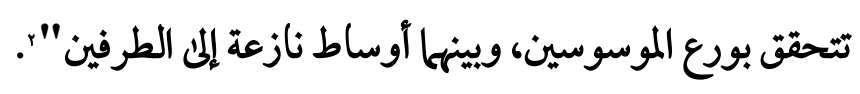

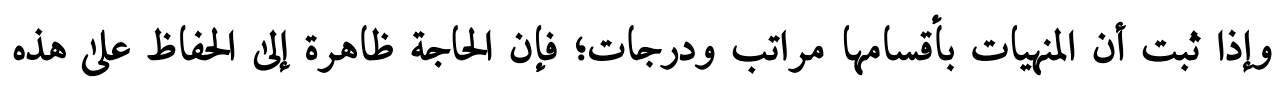
المستويات، لأن إلماق ما هو من مرتبة بأخرىأ عائد إلما إفراط أو تفريط. r.تشريع الرخص: الرخص: هي الأمكام الثابتة على خلاف الدليل لعذر، وقيل الرخصة: اسم لما بني على أعذار

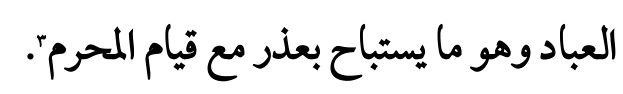
وقد اتفق جمهور العلماء على مشروعية الرخصيء فيا إذا وجدت أسبابها وتحققت دواعيها،

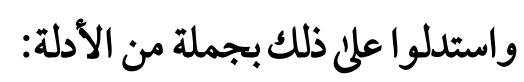

) (Y) الاعتصام / / Y T.

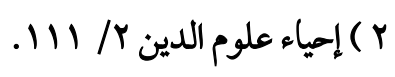

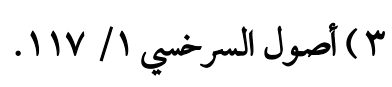

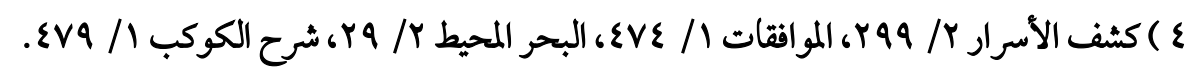




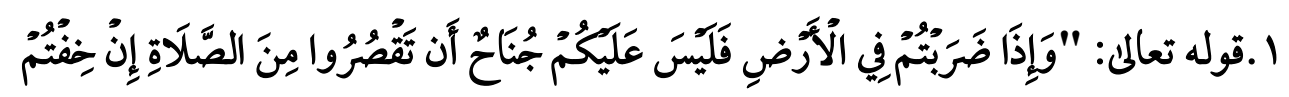

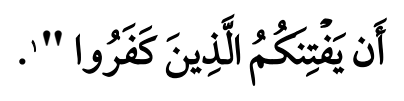

حيث دلت الآية على جواز قصر الصلاة للمسافر رخصة".

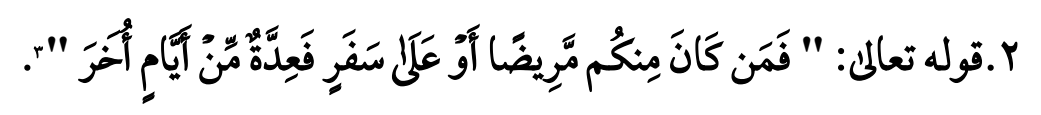

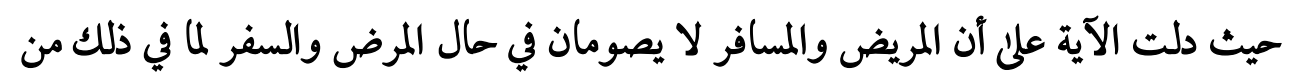
المشقة عليها، بل يفطران ويقضيان بعد ذلك من آيام أُخرء.

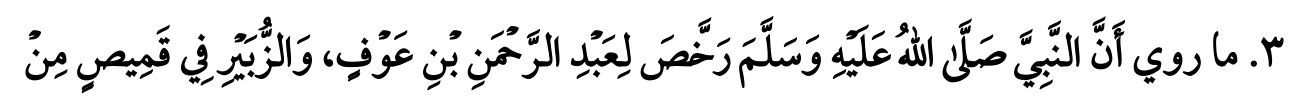

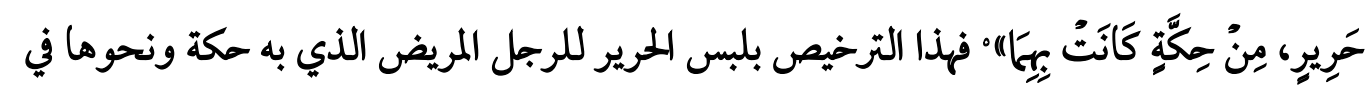
حال الضرورة، على الرغم من تحريمه في حال الصحة'.

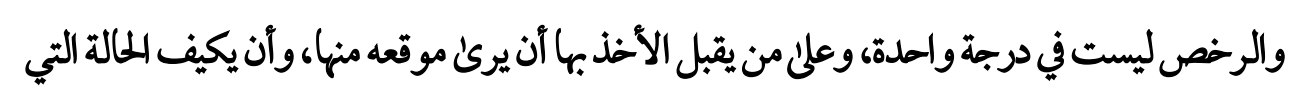

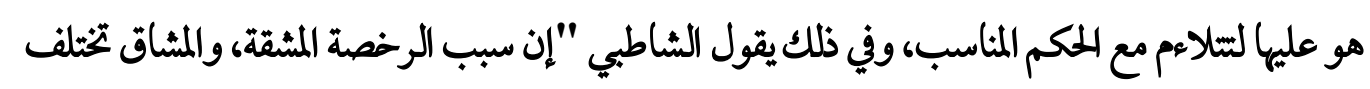
بالقوة والضعف، بحسب الأحوال، ويحسب قوة العزائموضعفها، ويحسب الأزمان، ويحسب الأعال،

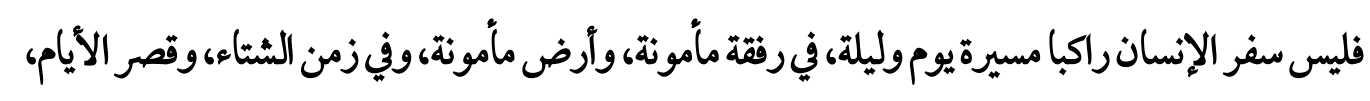

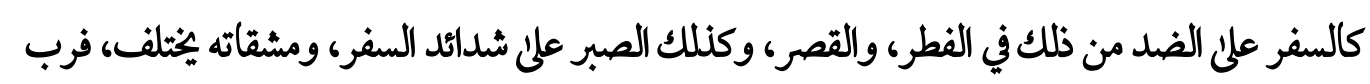

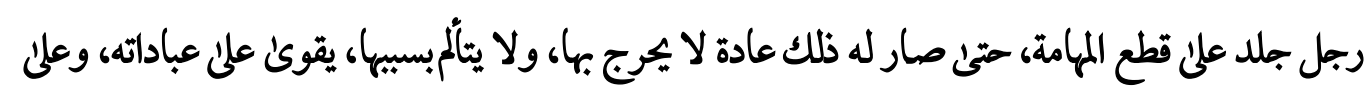

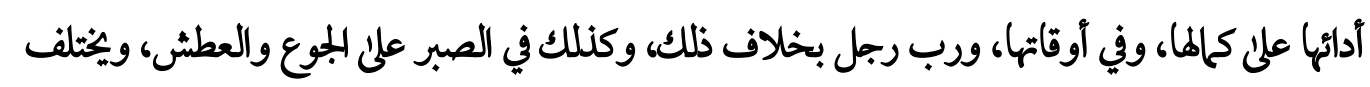

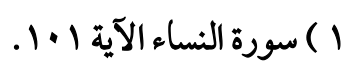

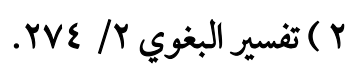

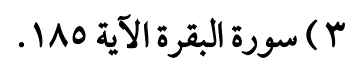

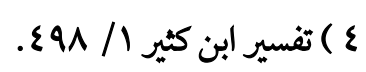

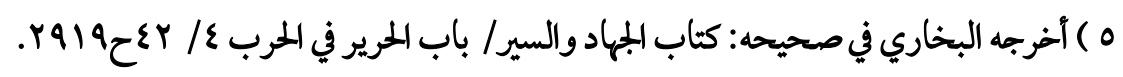

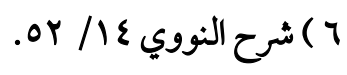


أيضا باختلاف الجبن والشجاعة، وغير ذلك من الأمور التي لا يقدر علن ضبطها، وكنلك المريض بالنسبة

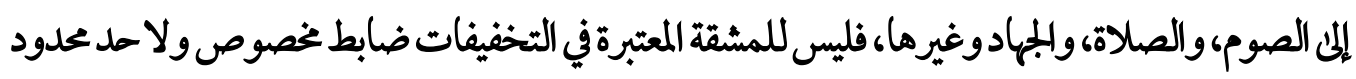

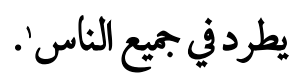
فالرخص أحكام استثنائية شرعها الله سبحانه وتعالمى مراعاة لحال الضرورة والحاجة، كرخص القصر والجمع في الصلاة، والفطر في رمضان حالة السفر والمرض، وتناول المحرمات حالة الاضطرار، والثيمم عند مشقة استعمال الماء. ومر اعاة الوسطية واضحة في تشريع هذه الاستيناءات؛ لأن الإنسان قد تعتريه حالات يعجز

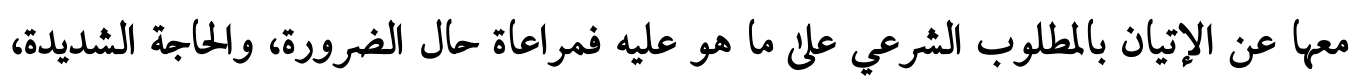
والعامة من وسطية الشريعة.

\section{ع.إبطال الحيل ـ2 الأحكام الشرعية}

اللحيل هي تقديم عمل ظاهر الجواز لإبطال حكم شرعي، وتحويله في الظاهر إلى حكم آخرّ.

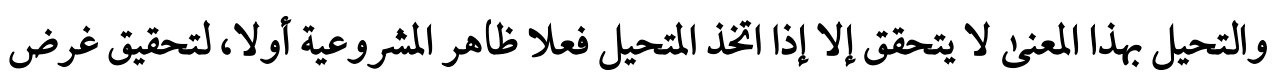

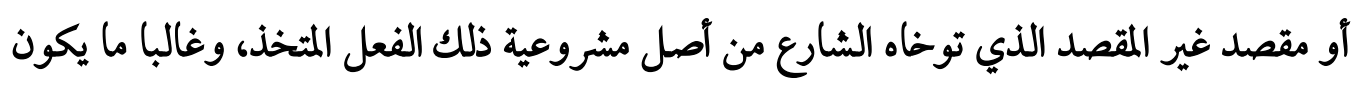

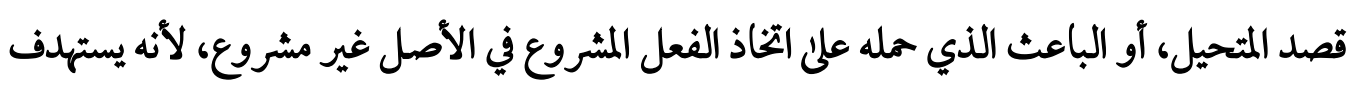

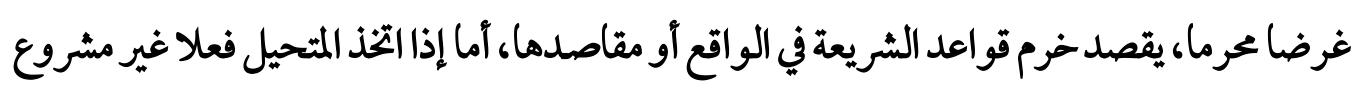
أصلا لتحقيق غرض غير مشروع، فهذا ليس من التحيل بل هو صريح في معاندة الشارعٌ.

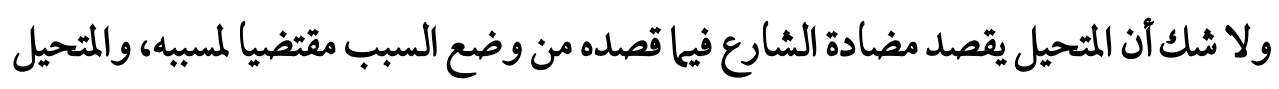
يناقض الشارع في جعله السبب لا يقتضي مسببه بإبطال حكم السبب؛.

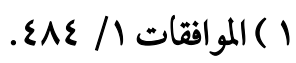

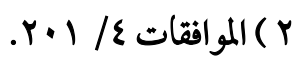

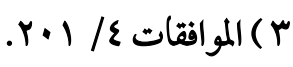

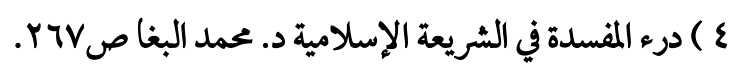


ولا يشك عاقل أن هذا الإبطال لحكم الشرع وقصده، لا يخرج بحال من دائرة الثفريط، والتقصير، والخروج عن هدي الوسط. 


\section{الإطلب الثاني : الوسطية في الأدلة الشرعية.}

الأدلة الشرعية التي تدرك منها الأمكام نوعان:

أدلة متفق عليها، وأدلة يختلف فيها.

فأما الأدلة المتفق عليها فهي: القرآن الكريم، والسنة النبوية، والإجماع، والقياس. وأما الأدلة المختلف فيها فكثيرة؛ فمنها: الاستحسان، والمصلحة المرسلة، وسد الذرائع،

$$
\text { والعرف، وقول الصحابي، وشرع من قبلنا ....إلى آخره. }
$$

وجميع هذه الأدلة الشرعية محققة لمبدأ الوسطية، وقد كان من عادة علماء الأصول عند تقعيدهم

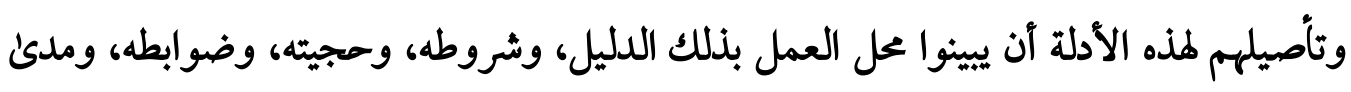

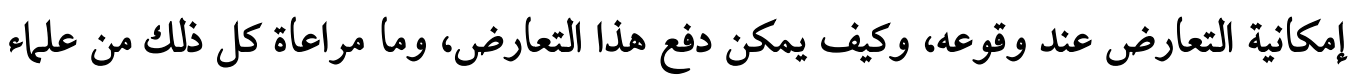
الأصول إلا مراعة لمنهج التوسط، فمثلا:

ا. منهج الأصوليين يج الفهم الصحيح لنصوص القرآن الكريم، والسنة النبوية انبنى على مراعاة ظواهر الألفاظ، ومدلولاتها في اللغة من جهة، ومعانيها وعللها التي سبقت لما من جهة ثانية، ومن دون ذلك يقع الإفراط والتفريط، وفي ذلك يقول ابن القيم: "أصحاب الرآي والقياس حملوا

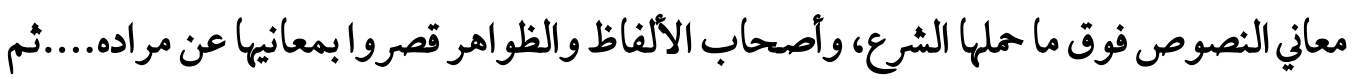

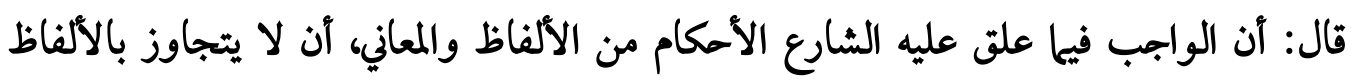
،ومعانيها، ولا يقصر بها، ويعطي اللفظ حقه، والمعنى حقه". وقد انتهوا ذات النهج في التعامل مع نصوص السنة النبوية؛ فالتوسط في فهمها يقتضي تمييز ما

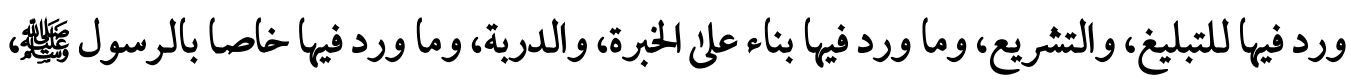

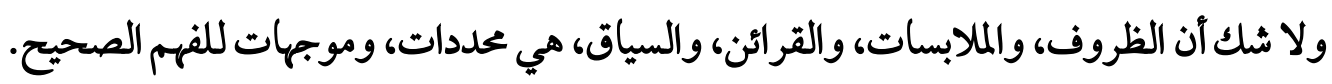

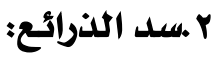


الذرائع: هي الأشياء التي ظاهرها الإباحة ويتوصل بها إلى فعل محذور' .

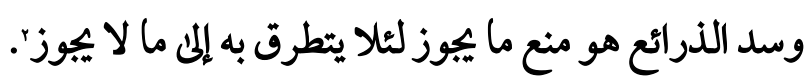

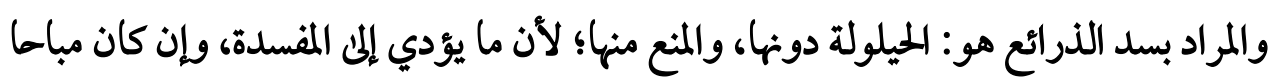

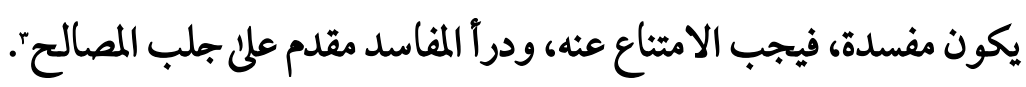
وسد الذرائع يحقق الوسطية؛ حيث يتجلن ذلك في النظر إلى نتائج الفعل، وثمرته، وأبعاده، وعدم الوقوف مع ما تقرر فيه من الجواز أو المنع، حيث آن سد الذرائع معناه منع الوسائل المؤدية إلى الثي

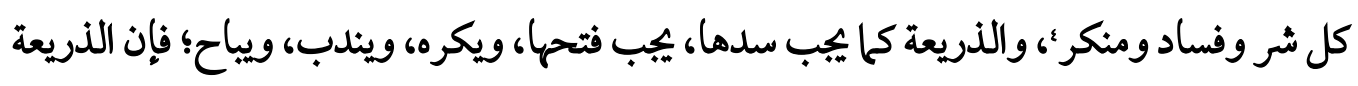
هي الوسيلة، فكما أن وسيلة المحرم محرمة، فوسيلة الواجب واجبةه r.بالاستحسان:

وهو أن يعدل المجتهد عن أن يكمم في المسألة بمثل ما حكم به في نظائرها إلى خلافه، لوجه آقوىن يقتضي العدول عن الأول، والاستحسان من أوضح الأدلة التي تقرر الوسطية، فجميع التعريفات التي ذكرها الأصوليون شاهدة على ذلك، ومن هذه التعريفات التي تثهد بذلك تعريفه بـ: العدول بالمسألة عن حكم نظائرها إلى حكم آخر، لوجه أقوى يقتضي العدول، فالاستحسان الذي يكثر

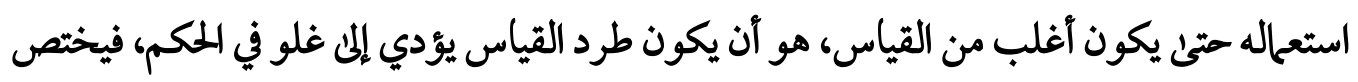

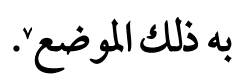

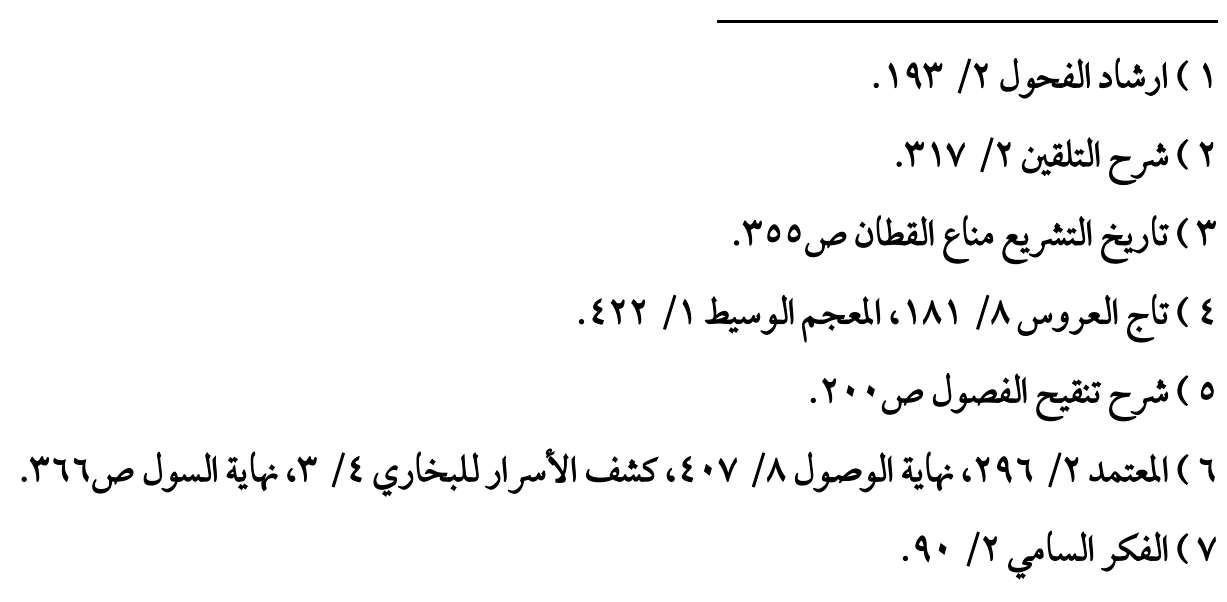




\section{ومعنى الاستحسان في أكثر الأحوال: الالتفات إلمى المصلحة والعدل. .}

والاستحسان استناء من قاعدة عامة؛ والباعث على هذا الاستيناء هو المد من الغلو الذي

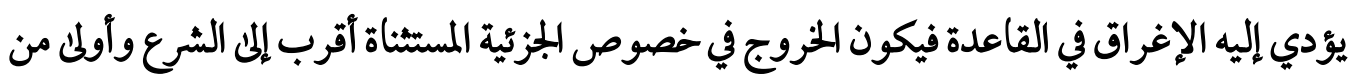
مراعاة الاطرادوهذا هو عين الوسطية. ع عـراعاة الخخلاف:

وهو إعطاء كل واحد من الدليلين المتعارضين ما يقتضيه الآخر، أو بعض ما يقتضيه'، وقيل: إنه إعمال دليل في لازم مدلوله، الذي أعمل في نقيضه دليل آخرّ. وهو إعادة نظر من المجتهد في الأمكام التي يقررها، وذلك بمراعاة دليل المخالف والنظر إلى لئل

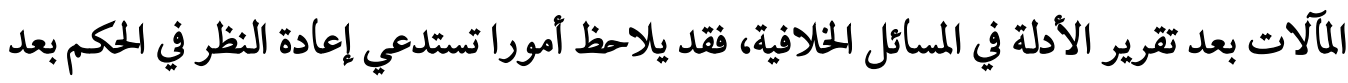
الوقوع خاصة، إذ حالة الاسمبعد الوقوع ليس كحالثه قبله، فبعد الوقوع تنشاً أمورا جديدة تستدعي نظر جديد، وتجد مشكلات لا يمكن التقصي عنها، إلا بالبناء على الأمر الواقع بالفعل، واعتباره شرعيا بالنظر لقول المخالف، وإن كان ضعيفا في أصل النظر، إلا إنه لما وقع الأمر علن مقتضاه روعيت المصلحة، وتجدد الاجتهاد في المسألة من جديد بنظر وأدلة أخرىناء،

فالفقيه ينزل عن بعض متطلبات رأيه ومقتضياته، إلى بعض ما يقتضيه رأي المخالف، فلا

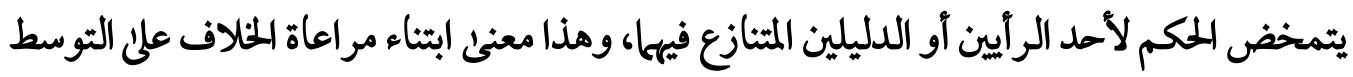
والاعتدال، وهو ما عبر عنه بلحكم بين المكمين، بل القضاء بالر اجح لا يقطع مكم المرجوح بالكلية،

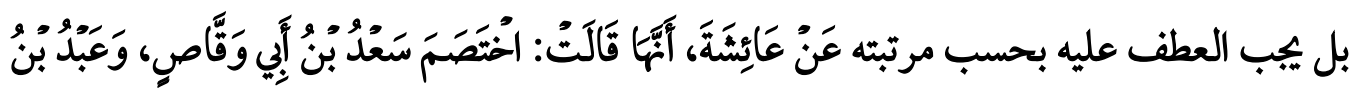

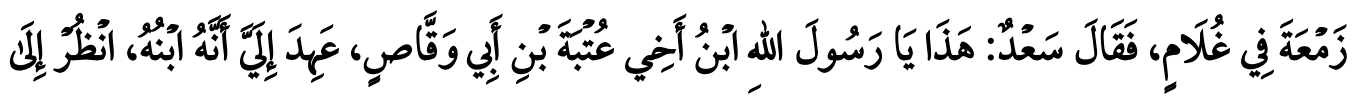

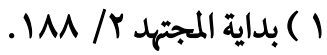

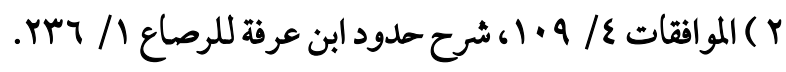

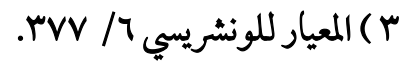

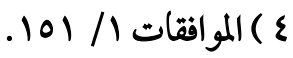




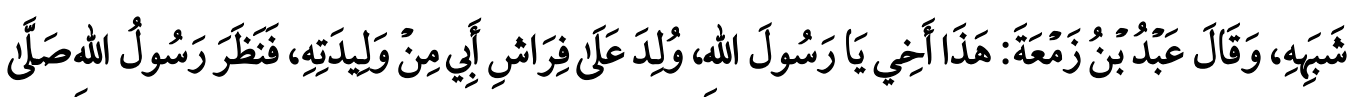

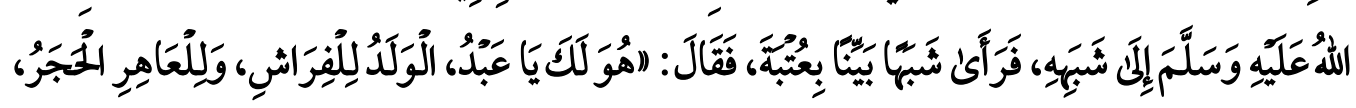

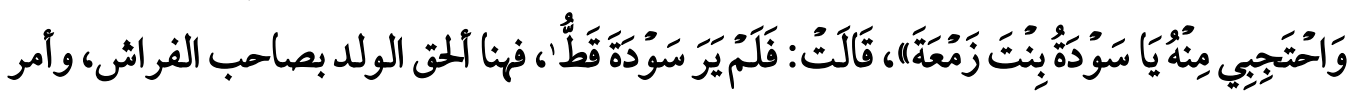

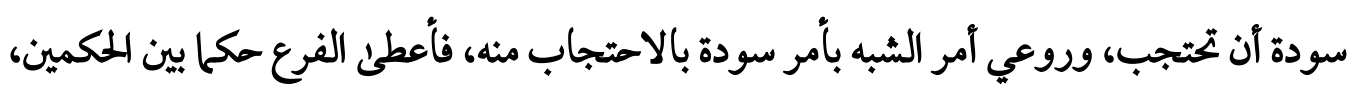
ولميمحض أمر الفراش فتبت المحرمية بينه ويين سودة، ولا راعلى أمر الشبه مطلقا فيلحق بعتبة.

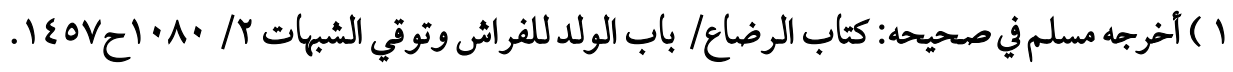

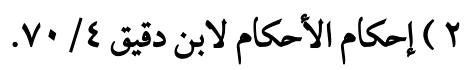




\section{الإملب الثالثه الوسطيلة في الاجتهاد}

الاجتهاد هو استفراغ الفقيه وسعه في تحصيل إدراك العلم، آو الظن بالحكم الشرعي على وجه

يكس من نفسه العجز عن المزيد'.

فهو الشريان اللحيوي الذي يمد الشريعة الإسلامية بالحياة، ويلبي جميع الاحتياجات التشريعية في كل زمان ومكان، فلحوادث والوقائع غير متناهية، والنصوص متناهية، وما لا يتناهيل يضبطه ما يتناهي، فعلم قطعا آن الاجتهاد والقياس واجب الاعتبار، حتى يكون بصدد كل حادثة اجتهاد'. وقد وضع علماء الأصول للاجتهاد ضوابط وشروط، تجعل منه اجتهاداً منضبطا غير ماتل إلى

$$
\begin{aligned}
& \text { طرف من الأطراف، إلا إذا كان الميل بسبب أو مصلحة. } \\
& \text { ومن ملامح الوسطية في الاجتهاد: }
\end{aligned}
$$

1.اعتبار التوسط ي2 اشتراط الصفات الواجب توافرها يِ المجتهد:

اشترط الأصوليون في الصفات الواجب توافرها في المجتهد شروطًا كثيرة؛ كلها مرتكزة في الوسط، فمثلا يقول إمام الحرمين عن شرط اللغة العربية: ولا يشترط التعمق والتبحر فيها حتى يصير الرجل علامة العرب، ولا يقع الاكتفاء بالاستظراف، وتحصيل المباديء والأطراف، بل القول الضابط في ذلك أن يحصل من اللغة العربية، ما يترقى به عن رتبة المقلدين في معرفة الكتاب والسنة، وهذا ما يستدعي منصبا وسطا في علم اللغة العربية". ويؤيد ذلك الغزالي قائلاً: "أما كتاب الله -عز وجل-فهو الأصل ولا بد من معرفته ولنخفف عنه أمرين:

أحدهم: : أنه لا يشترط معرفة جميع الكتاب؛ بل ما تتعلق به الأحكام منه وهو مقدار خمسمائة آية.

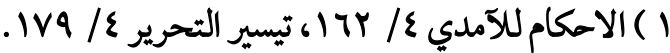

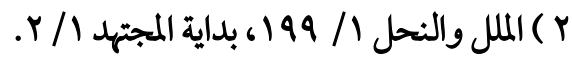

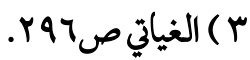


الثاني: لا يشترط حفظها عن ظهر قلب، بل أن يكون عالما بمواضعها بحيث يطلب فيها الآية

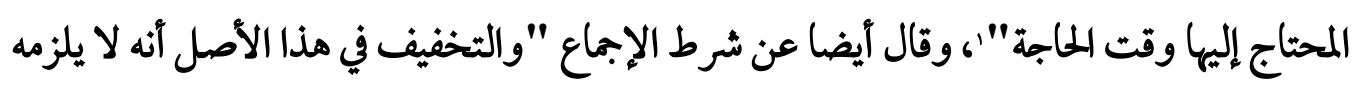

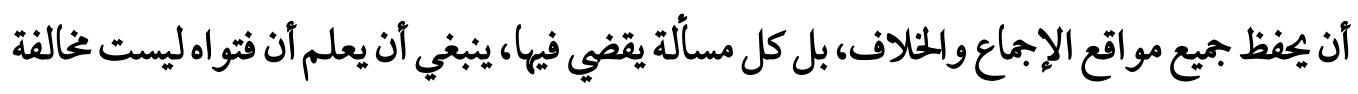
للإِماع"

وقد نص الشيخ (الحجوي) صراحة على درجة الوسطية فقال في المجتهد: "هو البالغ الزكي

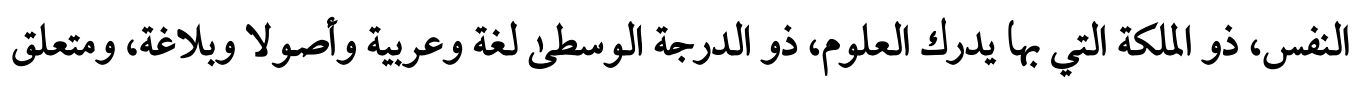

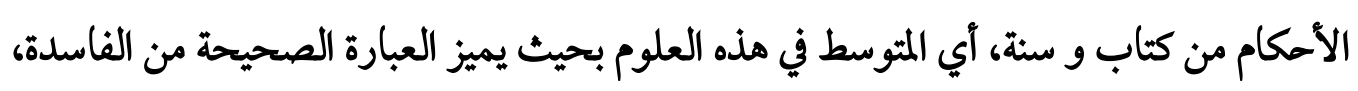
والراجحة من المرجوحة، ليتأتى له الاستنباط المقصود من الاجتهادي.

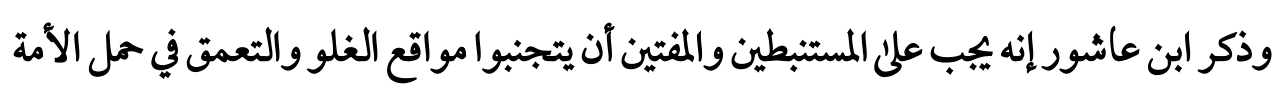
على الشريعة، وما يسن لما من ذلك، وهو موقف عظيمء ولما طلب من المجتهد أن لا يتبع مواقع الغلو والتشدد ليتحقق الاعتدال كان ذلك معناه

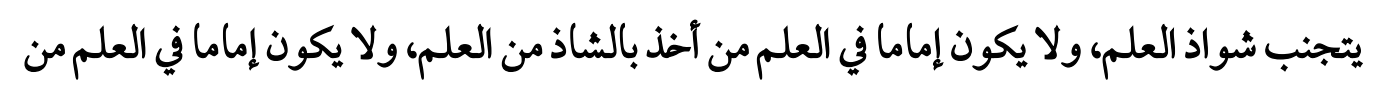

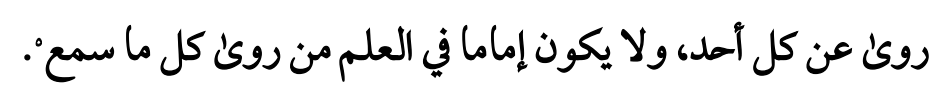
ب. الجمع بين الأدلة الكلية والأدلة الجزئية: فالتوسط في الاجتهاد يستلزم ضرورة المجمع بين الأدلة الكلية والأدلة الجزئية، وأن الانحراف

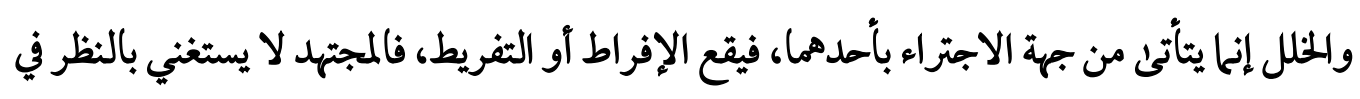

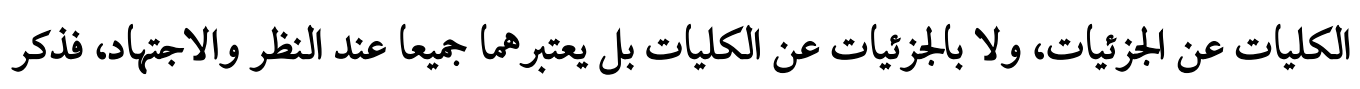

\footnotetext{
$\overline{~(1) ~(1) ~(1) ~}$ r r r المصدر السابق، نفس الموضع.

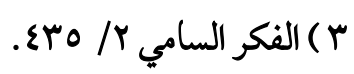
ع ) مقاصد الشريعة ص199.

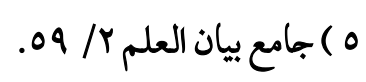


الشاطبي أن توجه الخطاب به علن المجتهد لا يتحقق إلا لمن اعتبر ذلك بحيث لا يصده التبحر في

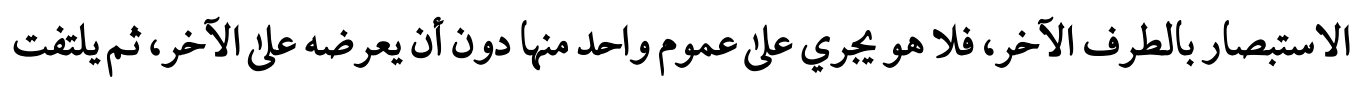
مع ذلك إلى تنزل ما تلخص له عليا ما يليق في أفعال المكلفين'.

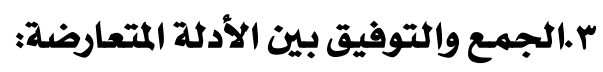

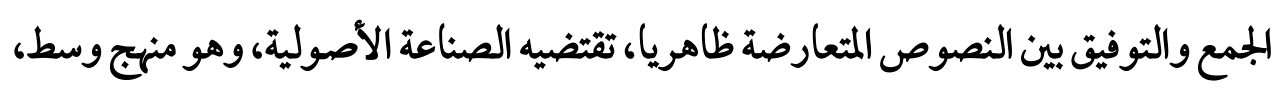
لأن الإعال أولى من الإهمال، وإعال الدليلين ولو من وجه واحد، أولى من إعال أحدهما وإهمال الآخر. واختيار التوسط معقل يلجاً إليه العلماء عند تعارض الأدلة أثناء مناقشته لما يحل ويحرم من

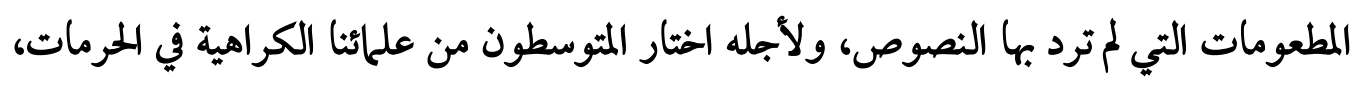
وتوسط) بين الحل والحرمة، لتعارض الأدلة.

( ) الموافقات \&/ 174.

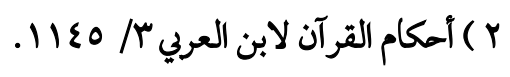




\section{المطلب الرابع : الوسطيل في التقاليل والفتوى.}

إن المستقريء للأحكام الشرعية يجدها جارية على التوسط والاعتدال، وما جاء على خلاف ذلك لا يعدو أن يكون استثناء من هذا الأصل الكلي اقتضاه علاج حالة المكلف. وتتضح ملامح الوسطية في باب التقليد والفتوى فيا يلي: ا.وجوب حمل المقلد على التوسط:

وإذا ثبت آن الحمل على التوسط هو الموافق لقصد الشارع، وهو الذي كان عليه السلف الصالح، فلينظر المقلد أي مذهب كان أجرى' على هذا الطريق فهو آخلق بالاتباع، وأولى بالاعتبار'. r. r.تغير الفتوى بتغير الزمان والمكان: فالشريعة الإسلامية قامت على الواقعية، والتيسير، ورفع الحرج، وراعت أحوال الناس، وظروفهم، وأزمنتهم، وأمكنتهم، ولذلك تتغير الفتوى بتغير الأزمنة، كالحكم بالتقاط ضوال الإبل، وإغلاق أبواب المساجد في غير وقت الصلاة، وأيضا تتغير بتغير الأمكنة، فالفتوى التي بنيت على وجود المستفتي في مكان معين تتغير بتغير المكان، كالمذهب المجديد والقديم للإمام الشافعي، والزواج بالكتابية في بلاد الغرب.

r.وضع علماء الأصول شروطا للصفات المؤهلة للإفتتاء لا ثطط فيها ولا تفريط منها: آ) آلا يقع المفتي تحت ضغط الواقع وتأثيره؛ فينساق وراء دنياه رغبة، أو رهبة، فتغدو مهمته تشريع الأحكام، والبحث عن المخارج، والحيل، فعلنى المفتي أن يفتي بالراجح أو المشهور. ب) العلم بالفروق بين المسائل أو القواعد المنقولة، والصور، والوقائع الحادئة، فكلم) لاحظ المفتي فرقا مؤثرا غيره لئلا ينحرف في تخريجه، وعلى المجتهد الحذر من أن ينظر المسائل بعضها ببعض ويخرج، وليس بصيرا بالفروق،. 
ع .معرفة أعراف الناس والتغيرات الطارئة على حياتهه: فإن المفتي البالغ الذروة هو الذي يحمل الناس على المعهود الوسط، فلا يذهب بهم مذهب الشدة، ولا يميل بهم إلى طرف الانحلال، والدليل على صحة هذا إنه الصراط المستقيم الذي جاءت به الشريعة، فإن مقصد الشارع من المكلف الحمل على التوسط؛ من غير إفراط ولا تفريط، فإذاخرج عن ذلك في المستفتين، خرج عن مقصد الشارع، ولذلك كان ما خرج عن المذهب الوسط مذموما عند العلماء الراسخين'.

والتزام المفتي للوسط في فتياه إنـا هو في حق المستفتين وجمهور الناس، وأما هو في خاصة نفسه فقد يسوغ له أن يحمل نفسه ماهو فوق الوسط، بشر ط آلا يظهره خشية آن يقتدي به'، فلمظنة الاقتداء هذه كان الراسخون في العلم يظهرون ما يليق بالجمهور مع علمهم أن ترك ذلك خير، خشية الانحراف عن الوسط. والتوسط في الإفتاء يكون بين التشديد والتخفيف، فلمستفتي إذا ذهب به مذهب التعنت والحرج بغض إليه الدين، وأدئ إلى الانقطاع عن سلوك طريق الآخرة، أما إذا ذهب به مذهب الانحلال، كان مظنة للمشي مع الموىئ والشهوة، والشرع إنها جاء بالنهي عن الموىن، واتباع الموىن مهلك، فالشأن إذا الأخذ بالوسط، وعدم الالثفات إلى الأطرافَ. 


\section{الغاتضة}

\section{نتائج البحث: \\ تبين من خلال البحث:}

1- الوسطية أصل يرجع إليه وقاعدة كبرئ يحتكم إليها، وكلية من كليات الشريعة.

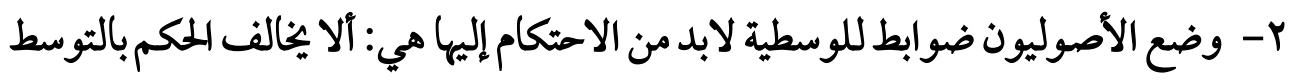

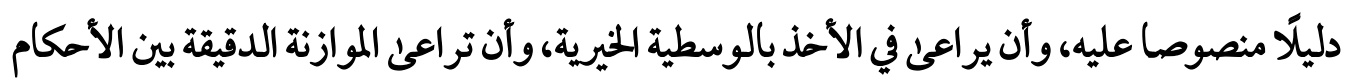
الشرعية.

ب- تعرف الوسطية بالشرع، والعقل، والعرف.

ع- علم أصول الفقه يحتكم لأسس مرجعية معبرة عن خصائص الوسطية في الشريعة الإسلامية والعية

إذ تتكامل فيه ثلاث أسس هي: الوحي، والعقل، والواقع.

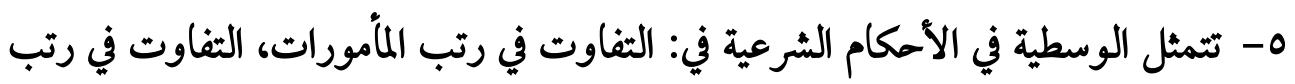

المنهيات، وفي تشريع الرخص، وإبطال الحيل في الأمكام الشرعية.

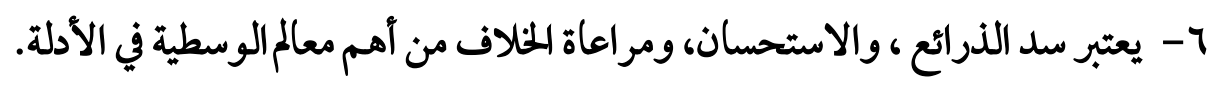

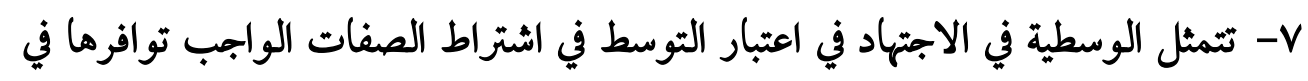

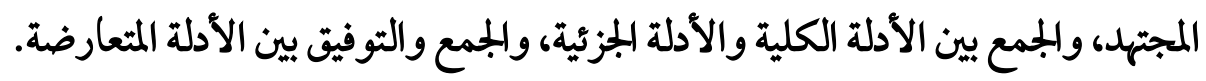

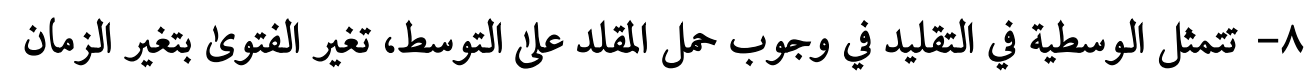

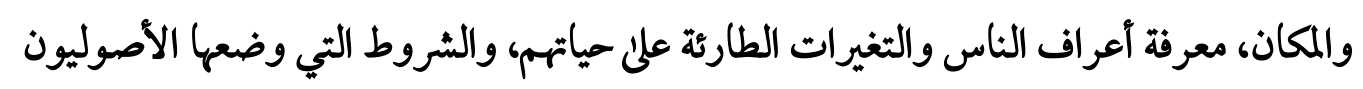
للصفات المؤهلة للإفتاء.

التتوهبات:

9- اهتمام المتخصحصين في علوم الشريعة الإسلامية لإظهار الو سطية في الأمكام الشرعية،

والفروع الفقهية.

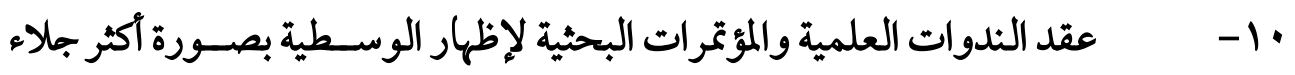
ووضوحًا في فقه العبادات، والمعاملات، والجنايات، والعلاقات الدولية.

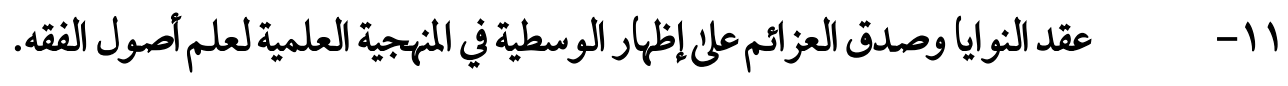

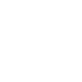




\section{ثبت بأهم المصادروالمراجع}

الإبهاج في شرح المنهاج على منهاج الوصول في علم الأصول للقاضي البيضاوي: لشيخ

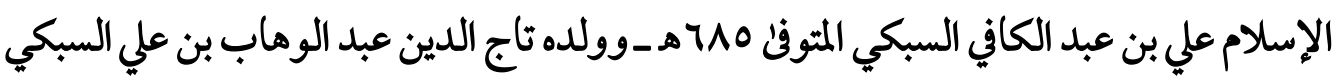

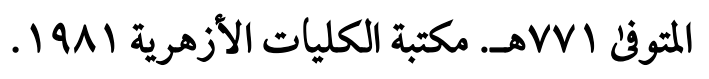

إمكام الأحكام لابن دقيق العيد، مطبعة السنة المحمدية، بدون.

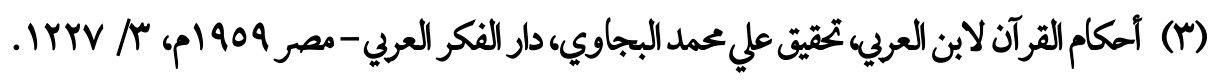

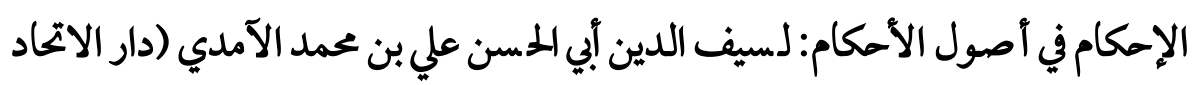

العربي للطباعة. مؤسسة الحلبي).

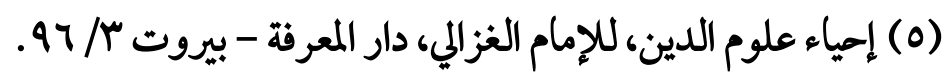

أدب الفتوئ وشروط المفتي وصـفة المسـتفتي وأحكامه وكيفية الفتوئ والاسـتفتاء

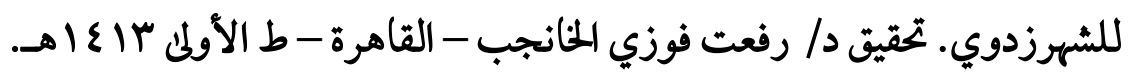

(V)

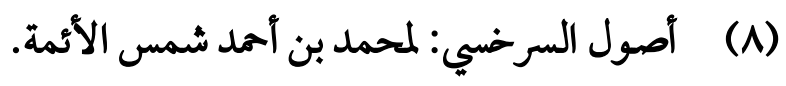

(9) الاعتصام، للشاطبي تحقيق: سليم بن عيد الملالي ، دار ابن عفان، السعودية الطبعة:

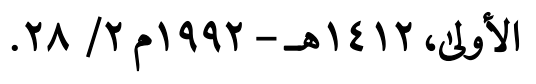

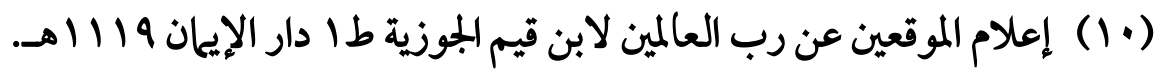

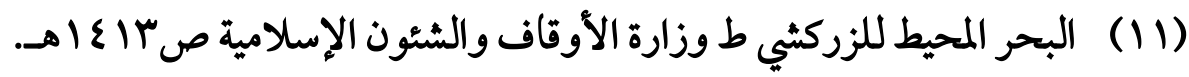

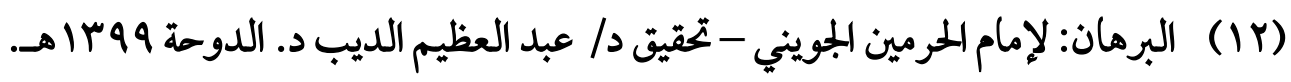

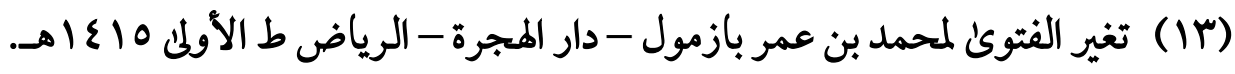

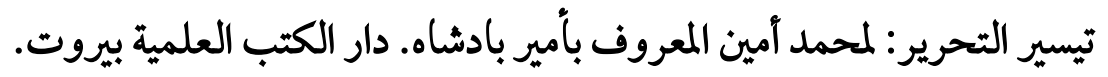

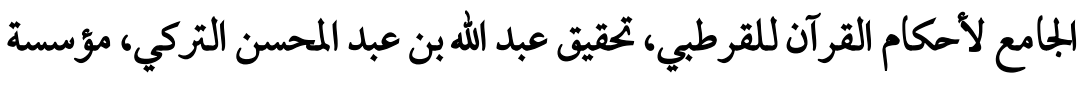

الرسالة ع / الv الv. 
الدر المثور في الثغسير المأثور، جلال الدين السيوطي، دار الفكر -بيروت 0 / 9 ؟ ؟.

شرح الإسنوي: لجمال الدين عبد الرحيم الإسنوي على منهاج الوصول للبيضاوي.

شرح العضد علئ مختصر ابن اللحاجب: تصحيح أ.د/ شعبان إسماعيل. مكتبة الكليات الأزهرية.

(19) شرح الكو كب المنير: للفتوحي الحنبلي المعروف بابن النجار. تحقيق محمد الزحيلي نزية

حماد (دار الفكر بدمشق + + ع (هـ).

شرح تنقيح الفصــول: للإمام شـهاب الدين أبي العباس القرافي. تحقيق طه سـعد عبد

$$
\text { الرؤوف. مكتبة الكليات الأزهرية. }
$$

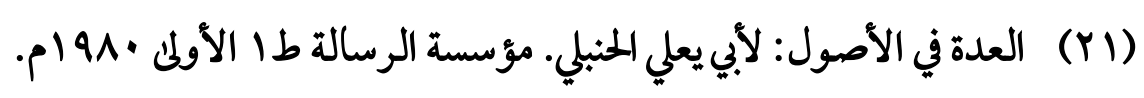

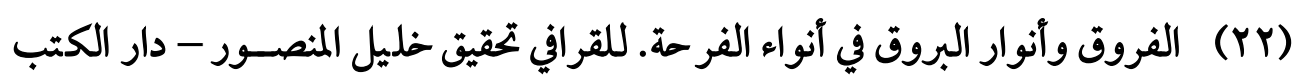
العلمية - بيروت ط الثانية · بع اهـ. الهـ

$$
\text { قواعد الأحكام، للعز بن عبد السلام، ط المعارف. }
$$

كشف الأسرار شرح أصول البزدوي للبخاري، دار الكتاب الإسلامي.

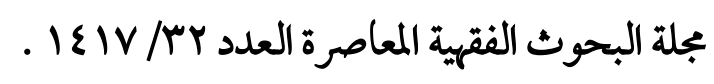

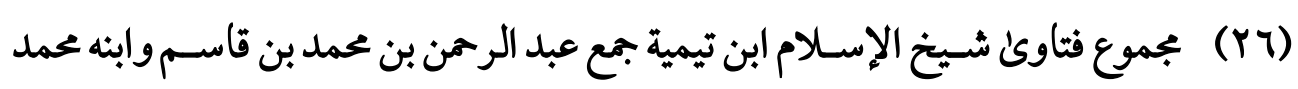

$$
\text { مكتبة المجلد العربي - القاهرة. }
$$

(rV)

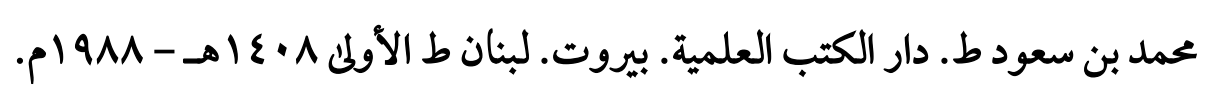
مدارج السالكين بين منازل اياك نعبد واياك نستعين، تحقيق شعيب الأرنؤوط ، مؤسسة (YA)

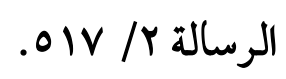

(YQ) المستصفي: في علم الأصول لحجة الإسلام أبي حامد الغزالي المطبعة الأميرية ط الأولى ع ب اهـ. (• ( المعتمد: لأبي الحسين محمد البصري. دار الكتب العلمية بيروت - تعليق خليل الميسي. 
ملامح الروية الوسطية في المنهج الفتهي، أبو أمامة نوار بن الشلي، وزارة الأوقاف

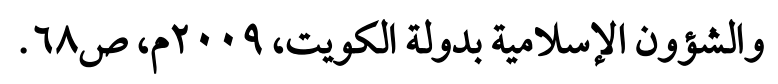

(Yr) (الموافقات في أصول الشريعة: لأبي اسحق الشاطبي. تحقيق الشيخ عبد اللدراز والطبعة

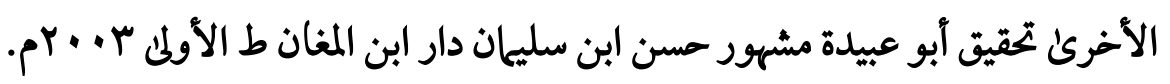

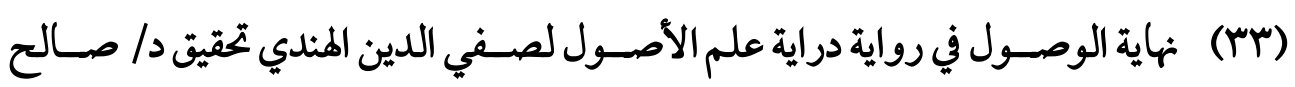
اليوسف. د/ سعد السويح مطبعة زار الباز - الرياض ط الثانية 999 ام. 
- IVTr - 